\section{ESTUDIO TECNOMORFOLÓGICO DE LA INDUSTRIA LÍTICA DE AMBRONA (SORIA)}

\author{
TECHNOMORPHOLOGICAL STUDY OF \\ THE LITIC INDUSTRY OF AMBRONA \\ (SORIA)
}

\author{
JOAQUÍN PANERA GALLEGO $(*)$ \\ SUSANA RUBIO JARA $(*)$
}

\section{RESUMEN}

Pese a la abundante bibliografía generada en torno a los depósitos pleistocenos de Ambrona, su industria lítica está escasamente documentada, hecho que se acentúa notablemente en el Complejo Superior, ya que sólo se ha publicado el número total de piezas de las que se compone su serie. Con este trabajo pretendemos paliar dicha carencia caracterizando tecnomorfológicamente la industria lítica de este importante sitio, y enmarcarla en el Achelense de la Península Ibérica. El Complejo Inferior, adscrito al Pleistoceno medio pleno, con industria Achelense, se sitúa en la órbita de El Sartalejo, La Maya II, Áridos o Torralba, y el Complejo Superior, adscrito al Pleistoceno medio superior o incluso a un momento posterior, con industria Achelense final, lo hace en torno a La Maya I o a la fase III de Atapuerca.

\begin{abstract}
In spite of the plentiful bibliography existent regarding the Pleistocene deposits of Ambrona, its lithic industry has been poorly documented. This fact becomes more marked in the "Upper Complex» of this site, where only a list with the total number of pieces contained in its sequence has been published. This paper tries to make up for this deficiency characterizing the lithic industry found in this important Pleistocene site in a technomor-
\end{abstract}

(*) Departamento de Prehistoria e Historia Antigua. Facultad de Humanidades. U.N.E.D. 28040. Madrid.

El artículo fue remitido en su versión final el 18-XI-96. phological framework and finally providing a setting for these lithic series in the Acheulian period of the Iberian Peninsula. "The Lower Complex», attributed to Middle Pleistocene with Acheulian artefacts, is situated in the El Sartalejo, La Maya II, Áridos or Torralba «orbit», and the "Upper Complex», attributed to Upper Middle Pleistocene or even to a latter moment with final Acheulian artefacts, is like La Maya I or phase III of Atapuerca.

Palabras clave. Pleistoceno medio. Achelense. Industria lítica.

Key words. Middle Pleistocene. Acheulian. Lithic industry.

\section{INTRODUCCIÓN}

Los depósitos pleistocenos de Ambrona, asociados tradicionalmente a los de Torralba, han generado abundante bibliografía, sobre todo desde que en 1961 Howell retomara las investigaciones iniciadas por el Marqués de Cerralbo a principios de siglo. Después de tres décadas en las que Howell y Freeman se hicieran cargo de estos yacimientos, y pese al largo período transcurrido desde que en 1983 concluyeran sus excavaciones, no se ha publicado ningún estudio en profundidad sobre aspectos como la geología, tafonomía y la industria lítica. De ésta disponemos 


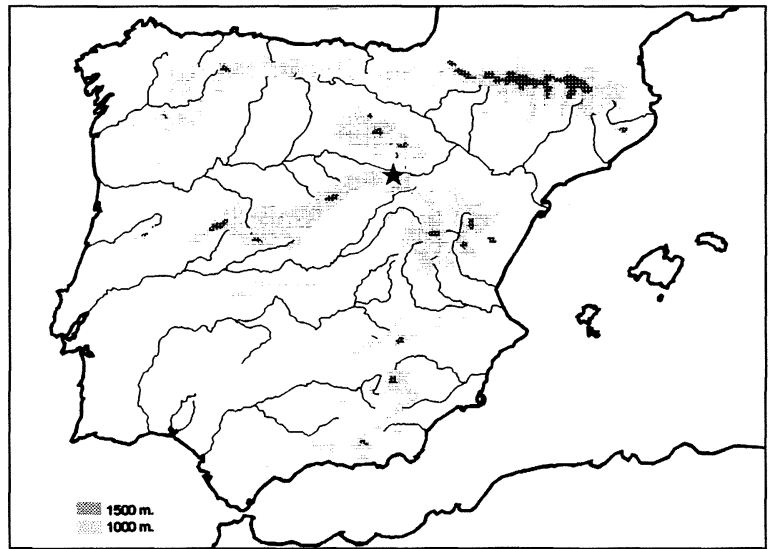

Fig. 1. Localización de Ambrona (Soria).

de estudios parciales y someros para el Complejo Inferior, mientras que para el Superior la información se limita al número total de piezas y al aspecto general de la industria (Freeman y Howell, 1982).

Ante la escasa información científica disponible para la interpretación de los citados yacimientos, D. Manuel Santonja Gómez y D. Alfredo Pérez González inician a principios de los noventa una nueva etapa investigadora. En este contexto se sitúa el presente trabajo (dentro del Proyecto PB93-0867 de la DGICYT), cuya finalidad es caracterizar tecnomorfológicamente la industria lítica de los Complejos Inferior y Superior de Ambrona, y enmarcarla en el Achelense de la Península Ibérica.

\subsection{Localización}

Ambrona se sitúa en el Sistema Ibérico a unos $1140 \mathrm{~m}$. sobre el nivel del mar y a 40-43 m. sobre el río Ambrona-Mansegal (drena en la actualidad el valle donde se ubican Torralba y Ambrona), en la divisoria de tres grandes cuencas hidrográficas: la del Duero al norte con el río Bordecorex, la del Ebro al sureste con el Jalón, en la que desemboca el Ambrona-Mansegal, y la del Tajo al suroeste con el Henares (Fig. 1). Desde un punto de vista regional el yacimiento se encuentra en la zona de cruce de estructuras del extremo oriental del Sistema Central en su límite con la Cordillera Ibérica. Fisiográficamente en la región destaca la superior capacidad erosiva remontante de los siste- mas fluviales del Ebro y Tajo respecto a la del Duero, que ha producido que a lo largo del Cuaternario hayan progresado hacia el norte, capturando valles o segmentos de valle, que inicialmente drenaban hacia el Duero (Pérez González et alii, 1995). Geográficamente se localiza en el SE de la provincia de Soria, a un kilómetro del pueblo que le da nombre. Sus coordenadas son $41^{\circ} 9^{\prime} 41^{\prime} \mathrm{N}$. y $2^{\circ} 29^{\prime} 48^{\prime} \mathrm{E}$. de la hoja de Maranchón número 462 del mapa topográfico nacional 1:50000, extendiéndose el valle Ambrona-Mansegal y la unidad de avenamiento a la hoja adyacente de Barahona número 434.

\subsection{Contexto geológico del yacimiento de Ambrona}

De más antiguos a más modernos afloran los siguientes materiales en la región: los tres pisos clásicos del Triásico (Buntsandstein, Muschelkalk y Keuper); Dolomías tableadas de Imón, Formación Carniolas de Cortes de Tajuña y Formaciones que alcanzan el Lias superior correspondientes al Jurásico; y arenas en facies utrillas correspondientes al Cretácico. Se reconocen tres superficies de erosión generalizadas, que Pérez González $(1991$; 1995) interpreta como las planicies M3, M2 y M1 de Schwenzner (1937), o las superficies B, C y D de Gladfelter (1971). Para el Pleistoceno inferior o medio antiguo no se identifican formas en la región, durante este período se produjo la degradación de M1 mediante alteración química y mecánica, evacuando por el Bordecorex, cuya divisoria hidrográfica podría haber alcanzado el paralelo de Torralba. La evolución del valle kárstico desmanteló la superficie carbonatada de M1 hasta el contacto estratigráfico entre las facies Keuper inferior y las Dolomías de Imón, constituyéndose un fondo amplio, impermeable y con débil pendiente hacia el norte. Este valle kárstico implicó "el descenso de los niveles freáticos locales hasta el contacto con el impermeable del keuper, produciéndose la descarga de los acuíferos colgados por numerosos manantiales al valle. La alimentación de los eventuales cauces que drenaban el valle del Bordecorex era principalmente de origen kárstico y dada las características geomorfológicas del fondo de valle el avenamiento muchas veces sería difuso lo que provocaría encharcamientos o acumulaciones

T. P., 54, n. ${ }^{\circ} 1,1997$ 
temporales de agua en depresiones topográficas de escasa profundidad" (Pérez González et alii, 1991). En este ambiente se produce la sedimentación de la formación de Ambrona, con facies de arenas, gravas y margas, que indican medios deposicionales fluviales y coluviales para las fases I, II y III, condiciones de medio palustres-lacustres para IV (Complejo Inferior); y detrítica, formada por depósitos de conos aluviales, para la $\mathrm{V}$ (siguiendo la estratigrafía planteada por $\mathrm{Bu}-$ tzer en 1965). El Complejo Inferior correspondería al Pleistoceno medio pleno, situándose en un momento posterior el Superior de Ambrona (Pérez González et alii, 1991).

\section{ESTRATIGRAFÍA}

En nuestro estudio analizamos la industria lítica de Ambrona documentada entre 1962 y 1983, y depositada en los museos Arqueológico Nacional y Numantino de Soria. A lo largo de este dilatado período Howell y Butzer emplearon diferentes secuencias estratigráficas en base a las que registraron la unidad en la sigla de los útiles líticos. La mayor parte de la industria se ajusta a la publicada por el segundo autor en 1965, la cual no difiere sustancialmente de las otras empleadas (Howell, 1965; Biberson, 1964), por lo que la empleamos en nuestra exposición. Butzer (1965) paraleliza los depósitos pleistocenos del yacimiento de Torralba con los de Ambrona, dividiéndolos en dos Formaciones: Formación Torralba, que afecta a ambos sitios, y Formación Sahuco, que sólo está presente en Torralba (Tab. 1). Ambrona presenta dos unidades bien diferenciadas geológica, cultural y cronológicamente denominadas Complejo Inferior y Complejo Superior. El Inferior se compone de las unidades II, III y IV de la Formación Torralba (la I no está presente en Ambrona), y el Superior de la V.

\section{METODOLOGÍA}

A través del análisis de la industria lítica pretendemos caracterizar una parte de la tecnología de los grupos humanos que ocuparon o merodearon en torno a Ambrona. Basamos su caracterización en la identificación de las cadenas operativas líticas. Compartimos las propuestas de

\begin{tabular}{|c|c|c|c|}
\hline \multirow{2}{*}{ Unidades } & \multirow{2}{*}{ Facies } & \multicolumn{2}{|c|}{ Espesores máximos (cm.) } \\
\hline & & Torralba & Ambrona \\
\hline $\begin{array}{l}\text { V d } \\
\text { V c } \\
\text { V b } \\
\text { V a } \\
\text { IV b } \\
\text { IV a } \\
\text { III b } \\
\text { III a } \\
\text { II d } \\
\text { II c } \\
\text { II b } \\
\text { II a } \\
\text { I }\end{array}$ & $\begin{array}{l}\text { FORMACIÓN SAHUCO } \\
\text { Aluvión fino oscuro } \\
\text { Aluvión basto marrón } \\
\text { Coluvión rojizo } \\
\text { Arenas amarillentas } \\
\text { Coluvión rojizo } \\
\text { Aluvión rojizo } \\
\text { Coluvión rojizo } \\
\text { Detritos crioclásticos } \\
\text { SUELO DE AMBRONA } \\
\text { (terra fusca) } \\
\text { Horizonte B } \\
\text { Horizonte C } \\
\text { Horizonte Ca. } \\
\text { FORMACIÓN TORRALBA } \\
\text { Aluvión basto rojizo } \\
\text { Aluvión fino rojizo } \\
\text { Gravas C } \\
\text { Marga arenosa } \\
\text { Marga gris } \\
\text { Marl with channel beds } \\
\text { Gravas B } \\
\text { Coluvio gris superior } \\
\text { Marga parduzca } \\
\text { Coluvio gris inferior } \\
\text { Gravas A } \\
\text { Arenas grises y arenosas } \\
\text { Coluvio rojo }\end{array}$ & $\begin{array}{r}80 \\
70 \\
125 \\
10 \\
55 \\
60 \\
30 \\
20\end{array}$ & $\begin{array}{r}95 \\
85 \\
60 \\
90 \\
200 \\
220 \\
15 \\
80 \\
150 \\
? \\
60 \\
400\end{array}$ \\
\hline
\end{tabular}

Tabla 1. Estratigrafía de Ambrona (Soria) publicada por Butzer en 1965: 1719.

Karlin (1991), quien en líneas generales sostiene que la cadena operativa pone en evidencia la lógica interna de una actividad, presentándose como un encadenamiento de actos, gestos e instrumentos, y constituyendo un proceso técnico con sus grandes etapas más o menos previsibles: es más la ordenación de las fases técnicas en series, que el camino técnico seguido por una materia prima desde el estado inicial de ésta hasta el producto finalizado. Estudiar las cadenas operativas «implica» diferenciar como los hombres organizan sus operaciones técnicas, es decir como las combinan dentro de uno o varios órdenes determinados. Boëda (Boëda et alii, 1990) defiende que en Europa durante el Paleolítico inferior y medio se suceden y cohesionan numerosas cadenas operativas, ante esta diversidad es necesario simplificar este concepto para que su utilización sea rentable científicamente en estos períodos. Las cadenas operativas pueden ser agrupadas 
bajo dos grandes principios: débitage y façonnage. El primero se define como el fraccionamiento de un volumen de materia prima, a través de una panoplia de métodos específicos, en diferentes unidades de formas y volúmenes que son obtenidas en series diferenciadas o estandarizadas. El segundo implica la adecuación de un volumen de materia prima concreto a una forma predeterminada, mediante la aproximación progresiva a dicha forma.

En base a estos dos principios distinguimos entre cadenas operativas de débitage (c.o.d.) y de façonnage (c.o.f.). Ciertas piezas participan de los dos principios: núcleos y productos retocados, hendedores, bifaces sobre lasca, etc. Son encuadrados y estudiados dentro de lo que denominamos cadenas operativas mixtas (c.o.m.), en tanto en cuanto se han obtenido mediante la aplicación del principio de débitage, pero su volumen ha sido adecuado posteriormente, participando por tanto del principio de façonnage. En el caso de los hendedores o bifaces sobre lasca creemos oportuno incluir su estudio dentro de las cadenas operativas de façonnage, considerando que, salvo excepciones, prima sobre manera la adecuación del volumen sobre la obtención del soporte, es decir la c.o.f. sobre la c.o.d.

- Cadenas operativas de débitage (c.o.d.). Están compuestas por núcleos y productos (lascas, debris y chunks). Mediante los primeros podemos identificar ciertos grupos de cadenas operativas, mientras que en función de los productos raramente lo podemos hacer (Tab. 2). En la diferenciación de estas c.o. partimos de la clasificación de núcleos de Santonja (1984a; 1986), y de los criterios establecidos por Boëda para los núcleos discoides y levallois (Boëda, 1986; 1988; 1990; 1993; Boëda et alii, 1990).

- Cadenas operativas mixtas (c.o.m.). Agrupan las piezas consideradas en la clasificación de Bordes, excluyendo los tipos que no pertenezcan a las cadenas operativas de débitage (cantos trabajados), y los que no están retocados (lascas levallois no retocadas). Las dividimos en los grupos clásicos.

- Cadenas operativas de façonnage (c.o.f.). Sólo es posible su diferenciación a través de los elementos formatizados - excepto en el caso de las lascas de avivado de bifaz- (Tab. 3).

\begin{tabular}{|l|l|l|}
\hline $\begin{array}{c}\text { Cadenas operativas } \\
\text { de débitage }\end{array}$ & Núcleos & \multicolumn{1}{c|}{ Productos } \\
\hline Muy elementales & Grupo I & Irreconocibles \\
\hline Elementales & Grupo II & Irreconocibles \\
\hline Piramidales & Grupo III & Irreconocibles \\
\hline Multifaciales & Grupo IV & Irreconocibles \\
\hline Bifaciales & Grupo V & Irreconocibles \\
\hline Discoides & Grupo VI & Lascas discoides \\
\hline Levallois preferenciales & Grupo VIIA & Lascas levallois preferenciales \\
\hline Levallois recurrentes & Grupo VII B & Lascas levallois recurrentes \\
\hline Kombewa & Grupo VIII & Lascas kombewa \\
\hline
\end{tabular}

Tabla 2. Composición de las cadenas operativas de débitage.

\begin{tabular}{|l|l|}
\hline Cadenas operativas de façonnage & \multicolumn{1}{|c|}{ Productos } \\
\hline Bifaciales & Lascas de avivado de bifaz \\
\hline De hendedores & Irreconocibles \\
\hline Triédricas & Irreconocibles \\
\hline De Cantos Trabajados & Irreconocibles \\
\hline
\end{tabular}

Tabla 3. Composición de las cadenas operativas de façonnage.

\section{CARACTERIZACIÓN TECNOMORFOLÓGICA}

La industria lítica con referencia estratigráfica definida en la sigla, correspondiente a las campañas realizadas por Howell y Freeman (1962, 1963, 1973, 1980 y 1981), y depositada en los Museos Arqueológico Nacional, Numantino de Soria y de Ambrona, está compuesta por 3150 piezas que se distribuyen estratigráficamente de forma muy desigual (Tab. 4).

\begin{tabular}{|c|r|r|c|r|c|}
\hline $\begin{array}{c}\text { Complejo } \\
\text { Inferior }\end{array}$ & Total & $\%$ & $\begin{array}{c}\text { Complejo } \\
\text { Superior }\end{array}$ & Total & $\%$ \\
\hline U. II & 91 & 7,1 & N. VA & 991 & 52,9 \\
U. III & 839 & 65,7 & N. VB & 883 & 47,1 \\
U. IV & 346 & 27,1 & & & \\
\hline Total & 1.276 & 100 & Total & 1.874 & 100 \\
\hline
\end{tabular}

Tabla 4. Distribución por unidades de la industria de Ambrona (Soria). 


\subsection{Complejo Inferior}

\subsubsection{Unidad II}

Implica una realidad estratigráfica compleja al estar compuesta por tres niveles correspondientes a ambientes sedimentarios muy diferentes (Butzer, 1965): arenas grises o IIa (potencia máxima de $400 \mathrm{~cm}$.), gravas A o IIb $(60 \mathrm{~cm}$.), y marga parduzca o IId $(150 \mathrm{~cm}$.). De las 91 piezas con las que cuenta, $62(68,1 \%)$ pueden integrarse en cadenas operativas de débitage, $21(23,1 \%)$ en c.o. mixtas, y $9(9,9 \%)$ en c.o. de façonnage. También hemos registrado dos percutores, de los que uno presenta carácter de núcleo (Tab. 5). En las materias primas predomina considerablemente la cuarcita $(60,3 \%)$ sobre el sílex $(37,9 \%)$ y la caliza $(1,7 \%)$. La única alteración registrada en la industria ha sido un ligero redondeamiento de las aristas [72,5\% R1 y 2,2\% R2 (1)], y desilicificación en dos piezas de sílex.

\subsubsection{Cadenas operativas de débitage (c.o.d.)}

Hemos identificado once núcleos (tres retocados), de los que se obtuvieron más de 87 lascas, sus dimensiones medias son: 53 x $43 \times 30 \mathrm{~mm}$. y 83 gr., y sus intervalos: $40 / 78 \times 22 / 68 \times 11 / 58 \mathrm{~mm}$. y 14/230 gr. Queda patente el predominio de los métodos discoides en la remoción de lascas (Tab. 6), y llama la atención la inexistencia de núcleos levallois, aunque el conocimiento de esta técnica

\begin{tabular}{|c|c|c|}
\hline Categorías & Total & $\%$ \\
\hline $\begin{array}{l}\text { Núcleos } \\
\text { Lascas } \\
\text { Debris } \\
\text { Chunks } \\
\end{array}$ & 4 & $\begin{array}{r}8, \\
4, \\
3, \\
11,\end{array}$ \\
\hline Total c.o.d. & 62 & 68,1 \\
\hline Útiles & 2 & 23 , \\
\hline Total c.o.m. & 21 & 23,1 \\
\hline $\begin{array}{l}\text { Bifaces } \\
\text { Hendedores } \\
\text { Triedros } \\
\text { C.T. }\end{array}$ & ( & $\begin{array}{l}6, \\
1,\end{array}$ \\
\hline Total c.o.f. & 7 & 7,7 \\
\hline Percutores & & 1 , \\
\hline Total & 9 & 10 \\
\hline
\end{tabular}

Tabla 5. Distribución de las categorías de la Unidad II (2) de Ambrona.

queda atestiguado por la documentación de dos lascas levallois preferenciales (Fig. 2.1). De las 58 lascas $17(29,3 \%)$ están retocadas y 20 cuentan con algún tipo de fractura (sólo se ha reconocido su causa en una pieza con doble rotura, ambas originadas por flexión), sus dimensiones medias son: 38 x 33 x $14 \mathrm{~mm}$. y sus intervalos: $17 / 58$ x 9/79 x $3 / 31 \mathrm{~mm}$. Están mayoritariamente descortezadas, aunque con un índice nada despreciable de piezas de segundo orden (Tab. 7). Su talón se ha reconocido en 40 piezas, su distribución sugiere una es-

\begin{tabular}{|l|l|r|r|r|r|r|}
\hline Cadenas operativas de débitage & Núcleos & Total & \% & Productos & Total & $\%$ \\
\hline Muy elementales & Grupo I & 0 & 0 & Irreconocibles & - & - \\
Elementales & Grupo II & 1 & 11,1 & Irreconocibles & - & - \\
Piramidales & Grupo III & 2 & 22,2 & Irreconocibles & - & - \\
Multifaciales & Grupo IV & 0 & 0 & Irreconocibles & - & - \\
Bifaciales & Grupo V & 1 & 11,1 & Irreconocibles & - & - \\
Discoides & Grupo VI & 4 & 44,4 & Lascas discoides & 0 & 0 \\
Levallois & Grupo VII & 0 & 0 & Lascas levallois & 2 & 3,5 \\
Kombewa & Grupo VIII & 1 & 11,1 & Lascas kombewa & 0 & 0 \\
\hline & Total & $\mathbf{9}$ & $\mathbf{1 0 0}$ & Total & & \\
\hline & Grupo IX & 1 & & & & \\
& Fragmentos & 1 & & & & \\
\end{tabular}

Tabla 6. Distribución de las cadenas operativas de débitage de la unidad II de Ambrona.

(1) R0: lados sin redondeamiento aparente; R1: ligero pero observable; R2: intenso.
(2) Núcleos, lascas y chunks retocados se incluyen sólo en la categoría utensilios; la pieza núcleo/percutor se considera con los núcleos.

T. P., 54, n. $^{\circ} 1,1997$ 


\begin{tabular}{|c|c|c|c|c|c|c|c|c|}
\hline \multicolumn{3}{|c|}{ Córtex (3) (N = 58) } & \multicolumn{3}{|c|}{ Talón $(\mathrm{N}=40)$} & \multicolumn{3}{|c|}{ Bulbo $(N=49)$} \\
\hline Tipo & Total & $\%$ & Tipo & Total & $\%$ & Tipo & Total & $\%$ \\
\hline 1 & 6 & 10.3 & Liso & 27 & 67.5 & Marcados & 15 & 30.6 \\
\hline $2 \mathrm{AG}$ & 1 & 1,7 & Cortical & 9 & 22,5 & Poco marcados & 26 & 53,1 \\
\hline $2 \mathrm{~A}$ & 10 & 17,2 & Diedro & 3 & 7,5 & No marcados & 2 & 4,1 \\
\hline $2 \mathrm{~B}$ & 3 & 5,2 & Facetado & 1 & 2,5 & No reconocibles & 6 & 12,2 \\
\hline $2 \mathrm{C}$ & 2 & 3,4 & & & & & & \\
\hline 3 & 36 & 62,1 & & & & & & \\
\hline
\end{tabular}

Tabla 7. Distribución del córtex, talón y bulbo de las lascas de la unidad II.

casa preparación de las superficies de percusión. El bulbo se ha determinado en 49 casos, estando principalmente poco o nada marcados (Tab. 7), lo que induce a pensar en la mayor utilización del percutor de poco peso frente a los pesados.

\subsubsection{Cadenas operativas mixtas}

U II cuenta con veintiuna piezas retocadas, en las que hay un claro predominio del sílex con 14 , 6 son de cuarcita y una de caliza. Sus dimensiones medias son $62 \times 47 \times 18 \mathrm{~mm}$., y sus intervalos: $34 / 119$ x 17/96 x 6/31 mm. Los soportes utilizados son en su mayoría lascas (17 frente a 3 núcleos, y un canto placa) que presentan dimensiones medias considerablemente superiores a las del lascado global ( 24 x 14 x 5 mm. más de media), pero similar corticalidad y plataformas de percusión. Tipológicamente (Tab. 8) hay un predominio claro del grupo II [52,9 de índice esencial (4), i.e. en adelante], seguido del IV (23,8\%; 23,5 de i.e.), mientras el III está marginalmente representado (5,9 de i.e.) (Fig. 2.2 y 3 ).

El retoque se muestra preferentemente en un sólo lado (en 15 ocasiones; en dos lados en 6), destacando el semiabrupto $(38,5 \%$ de los lados retocados, el $34,6 \%$ son abruptos, y el $26,9 \%$ simples), altera ligeramente la forma inicial del soporte, es normal respecto a su morfología (sólo se ha registrado uno laminar), directo en cuanto a su dirección (de los 27 lados sólo en 5 es inverso), y continuo conforme a su articulación (sólo en cuatro lados es discontinuo).

(3) 1-Anverso cubierto totalmente por córtex; 2AG-lascas de gajo de naranja; $2 \mathrm{~A}$-menos de un tercio del anverso cubierto por córtex; 2B-entre 1/3 y 2/3; 2C-más de 2/3; 3-lascas acorticales.

\begin{tabular}{|c|c|c|c|}
\hline Grupo & Clasificación & Total & $\%$ \\
\hline GRUPO II & $\begin{array}{l}\text { Raederas simples } \\
\text { Raederas transversales } \\
\text { Raederas dobles } \\
\text { Raederas desviadas } \\
\text { Raederas sobre cara plana } \\
\text { Raedera simple+escotadura } \\
\text { Afines a raederas } \\
\text { TOTAL }\end{array}$ & $\begin{array}{l}2 \\
1 \\
1\end{array}$ & $\begin{array}{r}9,5 \\
4,8 \\
4,8 \\
4,8 \\
9,5 \\
4,8 \\
\\
4,5 \\
47,6\end{array}$ \\
\hline GRUPO III & Raspador+escotadoras & 1 & 4,8 \\
\hline GRUPO IV & $\begin{array}{l}\text { Denticulados } \\
\text { Puntas de Tayac } \\
\text { TOTAL }\end{array}$ & $\begin{array}{l}4 \\
1\end{array}$ & $\begin{array}{rr} & 19,0 \\
& 4,8 \\
23,8 & \end{array}$ \\
\hline \multirow[t]{3}{*}{ GRUPO OTROS } & $\begin{array}{l}\text { Lascas retocadas } \\
\text { Escotaduras } \\
\text { TOTAL }\end{array}$ & $\begin{array}{l}3 \\
1\end{array}$ & $\begin{array}{r}14,3 \\
4,8 \\
19,1\end{array}$ \\
\hline & Fragmentos de útiles & 1 & 4,8 \\
\hline & TOTAL & 21 & 100 \\
\hline
\end{tabular}

Tabla 8. Clasificación de las cadenas operativas mixtas de la unidad II de Ambrona.

\subsubsection{Cadenas operativas de façonnage}

Son siete piezas en las que no hay triedros o cantos trabajados, y sólo un hendedor (de cuarcita y del tipo II), siendo bifaces los seis ejemplares restantes. En la materia prima es significativa la total ausencia de sílex, ya que cinco son de cuarcita y dos de caliza. Todos se realizaron a partir de cantos globulares mediante la utilización de percutores duros que se emplearon exclusivamente en cuatro piezas, y se alternaron en

(4) Aunque es aconsejable contar con un mínimo número de cien utensilios para estimar con fiabilidad éstos índices, los ofrecemos a modo complementario. 

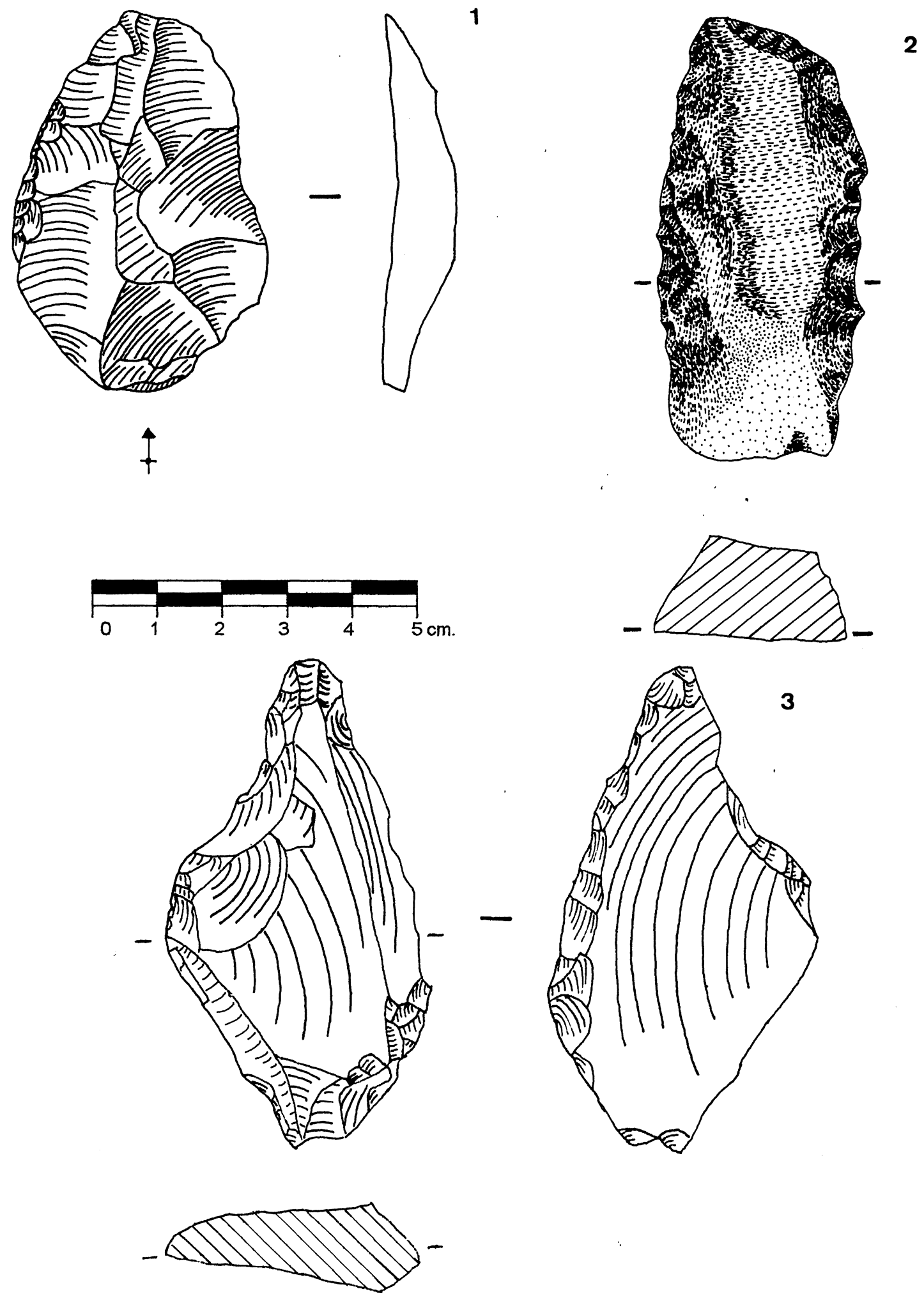

Fig. 2. Unidad II de Ambrona (Soria). 1. Lasca levallois preferencial. 2. Raedera doble. 3. Perforador atípico. 
dos con blandos (de los que uno exhibe el contorno reavivado por retoque). La talla es preferentemente amplia, proporcionando siluetas equilibradas, aristas sinuosas o ligeramente sinuosas, y secciones longitudinales biconvexas asimétricas. Los seis son espesos, y sólo uno puede clasificarse como parcial (Tab. 9). Durante su formatización se produjeron más de 104 lascas. Sus dimensiones medias son $124 \times 73$ x $45 \mathrm{~mm}$. y 410 gr. y sus intervalos: 108/153 x 49/80 x 28/55 mm. y $284 / 614$ gr.

\begin{tabular}{|c|l|c|c|}
\hline U. II & \multicolumn{1}{|c|}{ Siluetas } & Total & \% \\
\hline \multirow{2}{*}{ Espesos } & Amigdaloides & 2 & 33,3 \\
& Ovalares & 2 & 33,3 \\
& Limandes & 1 & 16,7 \\
\cline { 2 - 4 } & Total espesos & $\mathbf{5}$ & $\mathbf{8 3 , 3}$ \\
\hline Parciales & Ovalares espesos & 1 & 16,7 \\
\hline Total & & $\mathbf{6}$ & $\mathbf{1 0 0}$ \\
\hline
\end{tabular}

Tabla 9. Siluetas de los bifaces de la unidad II de Ambrona (Soria).

\subsubsection{Conclusiones}

La percusión se realizó con percutores de piedra de peso y forma adecuados. La composición general de la industria deja patente que las cadenas operativas se exhiben claramente incompletas, como demuestra que: las proporciones de las categorías de las c.o.d., pese a que estén representadas todas las propuestas, no son equilibradas (se han identificado un mínimo de 87 negativos en los núcleos mientras que sólo hay 58 lascas, los tres debris documentados conforman una exigua cifra para una muestra como la presente, etc.); en las c.o. de façonnage ni siquiera están presentes todas las fases, no habiéndose reconocido ni un sólo elemento derivado de la formatización de sus productos. Si tenemos en cuenta que durante la producción de bifaces se obtuvieron un mínimo de 104 lascas y las sumamos a las 87 proporcionadas por los núcleos, queda más patente, si cabe, la fragmentariedad de la industria de U II. No obstante la pertenencia de la serie a una misma población parece evidente, como demuestra el carácter general de la industria y que las materias primas y talones estimados en los negativos de los núcleos y los reales del lascado tengan porcentajes similares. Sin embargo no podemos afirmar lo mismo con los de los bifaces, al menos respecto a la materia prima.

\subsubsection{Unidad III}

La Unidad III responde a un panorama complejo de difícil interpretación geológica, al estar compuesta por diversos cuerpos sedimentarios. Butzer (1965) distingue dos niveles estratigráficos: «coluvio gris superior» o IIIa $(80 \mathrm{~cm}$. de espesor máximo), y «gravas b» o IIIb $(15 \mathrm{~cm}$.), que corresponden a ambientes sedimentarios diferenciados. Las cadenas operativas de débitage están representadas en el 76,9\% de los casos (645 piezas), las mixtas en el 19,7\% (165), y las de façonnage en el 3,4\% (29) (Tab. 10). En la distribución de las materias primas la cuarcita, aunque sigue siendo la más abundante $(50,7 \%)$, pierde representatividad frente a la caliza $(4,9 \%)$ y al grupo del sílex $(43,6 \%)$, en el que se han identificado ópalos, liditas, chert, y al menos diez variedades de sílex, también se documenta cuarzo $(0,7 \%)$. En cuanto al estado de la superficie cuatro piezas están patinadas (todas de sílex), la muestra aparece ligeramente rodada $(64,2 \% \mathrm{R} 1 \mathrm{y}$ $4,9 \%$ R2), y 34 desilicificadas en diferente grado (9,3\% del sílex).

\begin{tabular}{|c|c|c|}
\hline Categorías & Total & $\%$ \\
\hline $\begin{array}{l}\text { Núcleos } \\
\text { Lascas } \\
\text { Debris } \\
\text { Chunks } \\
\end{array}$ & $\begin{array}{r}30 \\
428 \\
80 \\
107 \\
\end{array}$ & $\begin{array}{r}3,6 \\
51,0 \\
9,5 \\
12,7\end{array}$ \\
\hline Total c.o.d. & 645 & 76,9 \\
\hline Útiles & 165 & 19,7 \\
\hline Total c.o.m. & 165 & 19,7 \\
\hline $\begin{array}{l}\text { Bifaces } \\
\text { Hendedores } \\
\text { Triedros } \\
\text { C.T. }\end{array}$ & $\begin{array}{r}22 \\
4 \\
0 \\
3\end{array}$ & $\begin{array}{r}2,6 \\
0,5 \\
0 \\
0,3\end{array}$ \\
\hline Total c.o.f. & 29 & 3,4 \\
\hline Percutores & 0 & 0 \\
\hline Total & 839 & 100 \\
\hline
\end{tabular}

Tabla 10. Distribución de las categorías de la unidad III de Ambrona (Soria). 


\subsubsection{Cadenas operativas de débitage}

La unidad III cuenta con 36 núcleos (22 de cuarcita, trece de sílex y uno de caliza), seis de ellos con retoque. Sus dimensiones medias son: 60 x 46 × $39 \mathrm{~mm}$. y $135 \mathrm{gr}$., y sus intervalos: $27 / 98$ x 22/79 x 8/52 mm. y 8/425 gr. Pese a que por tipos apreciamos una distribución más equitativa que en U II, continúan predominando los sistemas de remoción discoide, que junto con los desarrollados sobre lasca alcanzan la mitad de la muestra. Cabe destacar que casi el $11 \%$ son levallois (Tab. 11; Fig. 3.1). Las extracciones conservadas en los 36 núcleos superan las 225.

Las lascas son 583, de las que 155 están retocadas $(26,6 \%)$, y 7 exhiben seudorretoque $(1,2 \%)$. Sólo se ha reconocido tres productos de acondicionamiento (tres flancos de núcleo), y cuatro lascas con morfología laminar. Sus dimensiones medias son: $36 \times 31 \times 12 \mathrm{~mm}$. y sus intervalos: $12 / 112 \times 10 / 92 \times 2 / 41 \mathrm{~mm}$. El ta- lón se muestra poco elaborado, siendo en el sílex más complejo que en la cuarcita, y en el lascado retocado que en el lascado global, hecho que se acentúa en los productos identificadores de cadenas operativas de débitage. La baja proporción de bulbos pronunciados induce, en principio, a pensar en una mayor utilización de percutores livianos que de tipos pesados (Tab. 12). En 31 lascas $(5,2 \%)$ ha sido posible identificar su cadena operativa: catorce lascas levallois preferenciales (Fig. 3.2), ocho levallois recurrentes (Fig. 3.3,4 y 5), dos predeterminadas discoides, tres puntas seudolevallois (que se originan tanto en c.o. discoides, como c.o. levallois), y cuatro lascas kombewa. Los accidentes de talla son escasos: dos lascas sobrepasadas (ambas de sílex), 39 piezas con fractura Siret y 4 con bulbos gemelos. Hay 229 piezas que presentan algún tipo de fractura, seis se han originado por flexión, y en el resto la causa es indeterminada.

\begin{tabular}{|l|l|r|r|r|r|r|}
\hline Cadenas operativas de débitage & Núcleos & Total & $\%$ & Productos & Total & $\%$ \\
\hline Muy elementales & Grupo I & 3 & 10,7 & Irreconocibles & - & - \\
Elementales & Grupo II & 4 & 14,3 & Irreconocibles & - & - \\
Piramidales & Grupo III & 1 & 3,6 & Irreconocibles & - & - \\
Multifaciales & Grupo IV & 2 & 7,1 & Irreconocibles & - & - \\
Bifaciales & Grupo V & 1 & 3,6 & Irreconocibles & - & - \\
Discoides & Grupo VI & 7 & 25,0 & Lascas discoides & 2 & 0,3 \\
Levallois & Grupo VII & 3 & 10,7 & Lascas levallois & 22 & 3,8 \\
Kombewa & Grupo VIII & 7 & 25,0 & Lascas kombewa & 4 & 0,7 \\
\hline & Total & $\mathbf{2 8}$ & $\mathbf{1 0 0}$ & Total & $\mathbf{5 8 3}$ & \\
\hline & Grupo IX & 4 & & & & \\
\end{tabular}

Tabla 11. Distribución de las cadenas operativas de débitage de la unidad III.

\begin{tabular}{|c|c|c|c|c|c|c|c|c|}
\hline \multicolumn{3}{|c|}{ Córtex (N = 583) } & \multicolumn{3}{|c|}{ Talón $(\mathrm{N}=338)$} & \multicolumn{3}{|c|}{ Bulbo $(N=464)$} \\
\hline Tipo & Total & $\%$ & Tipo & Total & $\%$ & Tipo & Total & $\%$ \\
\hline 1 & 18 & 3,1 & Liso & 220 & 65,1 & Marcados & 96 & 20,7 \\
\hline $2 \mathrm{AG}$ & 23 & 3,9 & Cortical & 83 & 2,4 & Poco marcados & 247 & 53,2 \\
\hline $2 \mathrm{~A}$ & 69 & 11,8 & Diedro & 20 & 5,9 & No marcados & 39 & 8,4 \\
\hline $2 \mathrm{~B}$ & 46 & 7,9 & Facetado & 15 & 4,4 & No reconocibles & 82 & 17,7 \\
\hline $2 \mathrm{C}$ & 12 & 2,1 & & & & & & \\
\hline 3 & 415 & 71,2 & & & & & & \\
\hline
\end{tabular}

Tabla 12. Distribución del córtex, talón y bulbo de las lascas de la unidad III de Ambrona. 

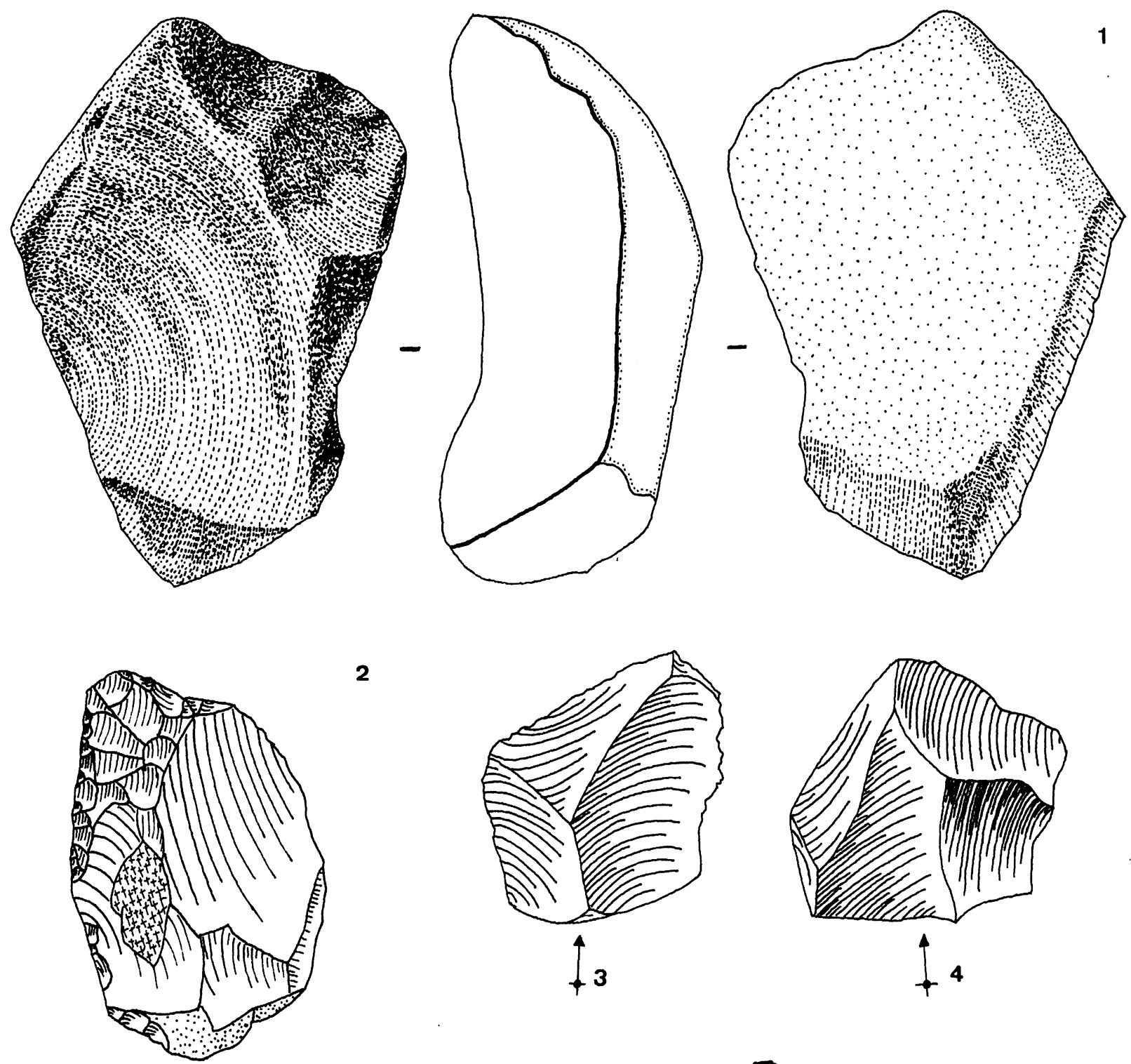

2
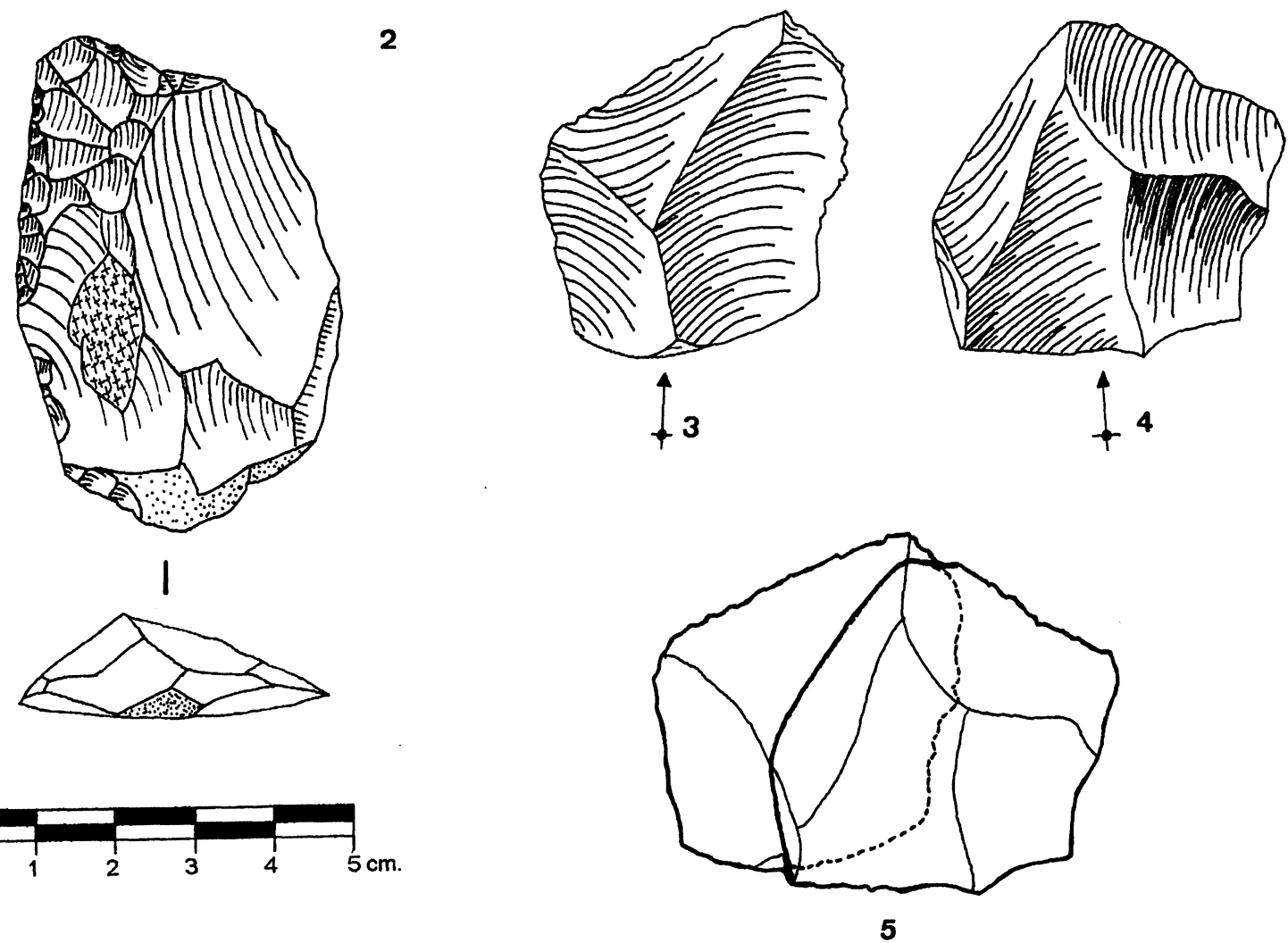

Fig. 3. Unidad III de Ambrona (Soria). 1. Núcleo del grupo VIIA (levallois de extracción preferencial). 2. Raedera simple sobre lasca levallois preferencial. 3. y 4. Lascas levallois recurrentes. 5. Remontaje de las lascas 3 y 4.

T. P., 54, n. ${ }^{\circ} 1,1997$ 


\subsubsection{Cadenas operativas mixtas (c.o.m.)}

U III cuenta con 165 piezas retocadas, de las que 106. son de sílex $(64,2 \%), 54$ de cuarcita $(32,7 \%), 3$ de caliza $(1,8 \%)$, y 2 de cuarzo $(1,2 \%)$. Sus dimensiones medias son: 42 x 37 x $14 \mathrm{~mm}$. y sus intervalos: 13/25 x 14/97 x 4/41 mm. En el 94\% de las piezas el soporte seleccionado para realizar estos útiles son lascas (165, frente a 6 núcleos, 3 chunks y 2 cantos), cuyas características técnicas apenas difieren del lascado global: similar corticalidad y plataformas de percusión, sólo el 3,9\% corresponden a cadenas operativas organizadas (13), etc., no obstante se prefiere el sílex a la cuarcita (20\% más que en el lascado global) y las lascas de mayor tamaño (dimensiones medias cerca de $7 \mathrm{~mm}$. superiores). El retoque es en más de la mitad de las ocasiones semiabrupto, siendo más comunes los abruptos que los simples; normal en cuanto a su morfología (sólo en tres piezas es laminar); de amplitud intermedia (47,9\% de los útiles), aunque también abunda la profunda $(33,6 \%)$; directo $(78,3 \%)$, son pocos los inversos $(12,4 \%)$, y aún menos los alternos (6\%) o bifaciales (en una pieza); y continuo respecto a su articulación $(89,4 \%)$. Casi una cuarta parte $(23 \%)$ exhiben dos lados retocados, siendo muy escasos los que presentan más de dos $(4,2 \%)$. Por grupos característicos (Tab. 13), predomina claramente el II con el $36 \%$ de la muestra ( 42,7 de i.e.), al que sigue el IV con el $31 \%$ (30,4 de i.e.), mientras el III sólo alcanza el $4 \%$ (6,5 de i.e.).

\subsubsection{Cadenas operativas de façonnage}

- Bifaces. Con veintidós ejemplares (9 de cuarcita, 8 de caliza y 5 de sílex), es la unidad con menor porcentaje de bifaces (13,2 de i.e.). Sólo uno cuenta con retoque secundario. Sus dimensiones medias son: 127 x 75 x $46 \mathrm{~mm}$. y 433 gr. y sus intervalos: $66 / 164$ x 36/108 x 22/78 mm. y $59 / 1050 \mathrm{gr}$. Se han formatizado mayoritariamente mediante percutores duros (en dos piezas exclusivamente, y en tres se alternaron con blandos). La talla es amplia, y proporciona siluetas generalmente equilibradas, aristas regulares en la mitad de la muestra y sinuosas en la otra mitad, y secciones biconvexas asimétricas. Son todos espesos, excepto dos (uno es parcial, y el soporte del otro es una lasca), y cinco son parciales (cuatro de ellos de caliza). Entre las siluetas dominan las

\begin{tabular}{|c|c|c|c|}
\hline Grupo & Clasificación & Total & $\%$ \\
\hline GRUPO II & \begin{tabular}{|l|} 
Limaces \\
Raederas simples \\
Raederas transversales \\
Raederas dobles \\
Raederas convergentes \\
Raederas desviadas \\
Raederas sobre cara plana \\
Raederas bifaciales \\
Raederas alternantes \\
Afines a raederas \\
TOTAL
\end{tabular} & $\begin{array}{r}1 \\
28 \\
10 \\
3 \\
5 \\
2 \\
3 \\
1 \\
3 \\
3\end{array}$ & $\begin{array}{r}0,6 \\
17,0 \\
6,1 \\
1,8 \\
3,0 \\
1,2 \\
1,8 \\
0,6 \\
1,8 \\
1,8 \\
35,8\end{array}$ \\
\hline GRUPO III & $\begin{array}{l}\text { Raspadores } \\
\text { Perforadores } \\
\text { cuchillos de dorso } \\
\text { TOTAL }\end{array}$ & $\begin{array}{l}2 \\
4 \\
1\end{array}$ & $\begin{array}{r}1,2 \\
2,4 \\
4,2\end{array}$ \\
\hline GRUPO IV & $\begin{array}{l}\text { Denticulados } \\
\text { Puntas de Tayac } \\
\text { Afines a denticulados } \\
\text { TOTAL }\end{array}$ & $\begin{array}{r}39 \\
\\
\quad 9 \\
51\end{array}$ & $\begin{array}{r}23,6 \\
5,5 \\
1,8 \\
30,9\end{array}$ \\
\hline GRUPO OTROS & $\begin{array}{l}\text { Lascas truncadas } \\
\text { Escotaduras } \\
\text { Becs } \\
\text { Afines a bec } \\
\text { Lascas retocadas } \\
\text { Afines a lascas retocadas } \\
\text { TOTAL }\end{array}$ & 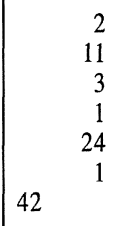 & $\begin{array}{r}1,2 \\
6,7 \\
1,8 \\
0,6 \\
14,5 \\
0,6 \\
25,5\end{array}$ \\
\hline $\begin{array}{l}\text { "ÚTILES" } \\
\text { COMPUESTOS }\end{array}$ & $\begin{array}{l}\text { Raedera simple+denticulado } \\
\text { Raedera doble+denticulado } \\
\text { Raspador+denticulado+bec }\end{array}$ & $\begin{array}{l}2 \\
1 \\
1\end{array}$ & $\begin{array}{l}1,2 \\
0,6 \\
0,6\end{array}$ \\
\hline & Fragmentos de útiles & 2 & 1,2 \\
\hline & TOTAL & 165 & 100 \\
\hline
\end{tabular}

Tabla 13. Clasificación de las cadenas operativas mixtas de la unidad III de Ambrona (Soria).

de aspecto subcircular a las que siguen las amigdaloides, mientras que de aspecto lanceolado sólo hay una (Tab. 14). De los 21 ejemplares se obtuvieron un mínimo de 339 lascas.

- Hendedores. Solamente hay cuatro $(2,4$ de i.e.), de morfología equilibrada aunque de técnica simple (tres del tipo II, y uno del V atípico, tendente al 0), dos de sílex y dos de cuarcita. Constituyen los «utensilios» de mayor tamaño (141 x 96 x $43 \mathrm{~mm}$. de media). Los percutores empleados en su formatización fueron duros, aunque en dos casos pudieron haber sido alternados con blando.

- Cantos trabajados. Son tres $(10 \%$ de las c.o.f., 1,8 de i.e.). Con morfología y formatizaciones muy elementales: dos de caliza con filo simple y unifaciales, y otro de cuarcita con filo simple y bifacial. 


\begin{tabular}{|c|c|c|c|}
\hline Unidad III & Siluetas & Total & $\%$ \\
\hline Planos & Limaces & 1 & 4,8 \\
\hline \multirow[t]{2}{*}{ Espesos } & $\begin{array}{l}\text { Amigdaloides } \\
\text { Ovalares } \\
\text { Limandes }\end{array}$ & $\begin{array}{l}4 \\
2 \\
2\end{array}$ & $\begin{array}{r}19,0 \\
9,5 \\
9,5\end{array}$ \\
\hline & Total Espesos & 8 & 34,1 \\
\hline \multicolumn{2}{|r|}{ Filo transversal } & 4 & 190 \\
\hline \multirow[t]{2}{*}{ Parciales } & $\begin{array}{l}\text { Limandes } \\
\text { Ficrones lanceolados } \\
\text { Amigdaloides } \\
\text { Ovalares espesos } \\
\end{array}$ & $\begin{array}{l}1 \\
1 \\
1 \\
2\end{array}$ & $\begin{array}{l}4,8 \\
4,8 \\
4,8 \\
9,5\end{array}$ \\
\hline & Total parciales & 5 & 23,8 \\
\hline \multicolumn{2}{|r|}{ Abbevillenses } & 1 & 23,8 \\
\hline \multicolumn{2}{|r|}{ Nucleiformes } & 2 & 9,5 \\
\hline \multicolumn{2}{|l|}{ Total } & 21 & 100 \\
\hline Fragmentos & Punta de bifaz & 1 & \\
\hline Total & & 22 & \\
\hline
\end{tabular}

Tabla 14. Siluetas de los bifaces de la unidad III de Ambrona (Soria).

\subsubsection{Conclusiones}

Aunque es la unidad con más industria la densidad sigue siendo muy baja, y faltan elementos de las cadenas operativas. En las de débitage en un primer momento no se plantean problemas en la cantidad de lascas estimadas mediante los negativos de los núcleos con las documentadas, ni siquiera si les sumamos las consideradas para los bifaces y cantos trabajados (583 lascas reales, frente a las 577 estimadas), pero cabe considerar que núcleos y bifaces se muestran en un avanzado estado de desbastado, por lo que reflejan una mínima parte de los elementos que han producido. En segundo lugar los productos identificadores de cadenas operativas no coinciden con los estimados en sus respectivos núcleos (se han estimado 10 lascas kombewa, pero sólo hay cuatro núcleos, etc.). En tercer lugar carecemos de lascas corticales de primer orden y en menor medida de segundo, lo que podría apuntar que la materia prima es introducida en el yacimiento con el proceso de desbastado iniciado. Del mismo modo tampoco hay núcleos de los que se hayan podido extraer los hendedores, aunque cabe la posibilidad de que fueran reexplotados hasta reducir considerablemente sus dimensiones.
Pese a estas circunstancias podemos asegurar que las cadenas operativas de débitage pertenecen a una misma población, en función de las materias primas, talones y dimensiones de las extracciones estimadas en los núcleos con los reales, las cuales guardan una relación coherente. Sin embargo no sucede así con las de façonnage, que junto a la carencia de lascas y núcleos relacionados con estas cadenas operativas induce a considerar la posibilidad de que sus elementos característicos fueran introducidos ya elaborados en el yacimiento.

\subsubsection{Unidad IV}

A diferencia de las unidades precedentes U IV responde a un mismo ambiente sedimentario, lacustre-palustre, en el que a lo sumo se han diferenciado facies. En U IV hay dos unidades: «margas con lentejones de gravas» o IV a (con espesor máximo de $220 \mathrm{~cm}$.) y «marga gris» o IV b $(200 \mathrm{~cm}$.) que es arqueológicamente estéril. Cuenta con 346 piezas, de las que más de tres cuartas partes, $246(71,1 \%)$, pueden incluirse en cadenas operativas de débitage, $81(23,4 \%)$ en mixtas y $19(5,5 \%)$ en las de façonnage (Tab. 15). Es la única unidad en la que los valores del grupo del sílex (en el que se ha identificado ópalo, lidita, y al menos nueve variedades de sílex) son superiores a los de la cuarcita $(54,2 \%$, frente

\begin{tabular}{|c|c|c|}
\hline Categorías & Total & $\%$ \\
\hline $\begin{array}{l}\text { Núcleos } \\
\text { Lascas } \\
\text { Debris } \\
\text { Chunks } \\
\end{array}$ & $\begin{array}{r}18 \\
141 \\
43 \\
44 \\
\end{array}$ & $\begin{array}{r}5,2 \\
40,7 \\
12,4 \\
12,7 \\
\end{array}$ \\
\hline Total c.o.d. & 246 & 23,4 \\
\hline Útiles & 81 & 23,4 \\
\hline Total c.o.m. & 81 & 4,3 \\
\hline $\begin{array}{l}\text { Bifaces } \\
\text { Hendedores } \\
\text { Triedros } \\
\text { C.T. }\end{array}$ & $\begin{array}{r}15 \\
2 \\
1 \\
1\end{array}$ & $\begin{array}{l}4,3 \\
0,6 \\
0,3 \\
0,3\end{array}$ \\
\hline Total c.o.f. & 19 & 5,5 \\
\hline Percutores & 0 & 0 \\
\hline Total & 346 & 100 \\
\hline
\end{tabular}

Tabla 15. Distribución de la industria de la unidad IV de Ambrona (Soria). 

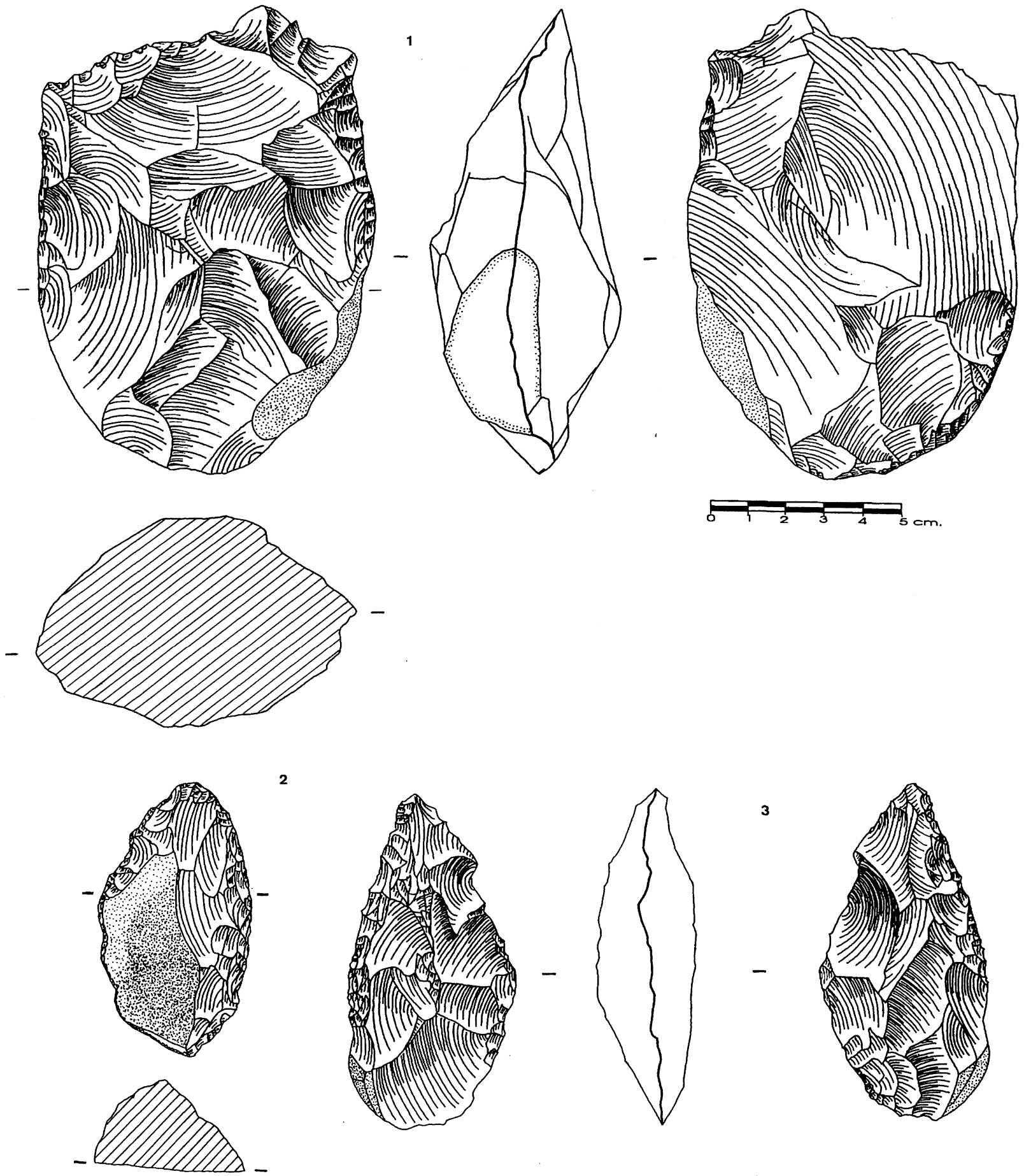

3

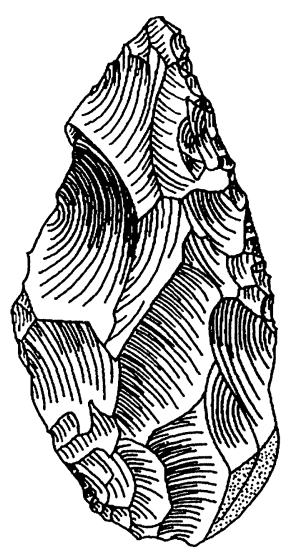

Fig. 4. Unidad IV de Ambrona (Soria). 1. Hendedor tipo II. 2. Limace. 3. Ficrón lanceolado.

T. P., 54, n. ${ }^{\circ} 1,1997$ 


\begin{tabular}{|l|l|r|r|r|r|r|}
\hline Cadenas operativas de débitage & Núcleos & Total & $\boldsymbol{\%}$ & Productos & Total & \% \\
\hline Muy elementales & Grupo I & 0 & 0 & Irreconocibles & - & - \\
Elementales & Grupo II & 1 & 6,3 & Irreconocibles & - & - \\
Piramidales & Grupo II & 1 & 6,3 & Irreconocibles & - & - \\
Multifaciales & Grupo IV & 1 & 6,3 & Irreconocibles & - & - \\
Bifaciales & Grupo V & 0 & 0 & Irreconocibles & - & - \\
Discoides & Grupo VI & 5 & 31,2 & Lascas discoides & 0 & 0 \\
Levallois & Grupo VII & 3 & 18,7 & Lascas levallois & 6 & 2,8 \\
Kombewa & Grupo VIII & 5 & 31,2 & Lascas kombewa & 3 & 1,4 \\
\hline & Total & $\mathbf{1 6}$ & $\mathbf{1 0 0}$ & Total & & \\
\hline & Grupo IX & 4 & & & & \\
& Fragmentos & 1 & & & & \\
\end{tabular}

Tabla 16. Distribución de las cadenas operativas de débitage de la unidad IV de Ambrona.

a $39,7 \%, 5,5 \%$ para la caliza, y $0,6 \%$ para el cuarzo). En cuanto al estado de superficie sólo hay una pieza patinada (de sílex), diecisiete desilicificadas ( $9 \%$ del sílex), y la serie se exhibe ligeramente redondeada (69\% $\mathrm{R} 1,3,8 \% \mathrm{R} 2)$.

\subsubsection{Cadenas operativas de débitage}

Se han identificado veintiún núcleos (11 de cuarcita, 8 de sílex y 2 de caliza), de los que se obtuvieron un mínimo de 142 lascas y tres fueron retocados. Sus dimensiones medias son: 58 x $45 \mathrm{x}$ 26 mm. y 93 gr. y sus intervalos: 24/106 x 20/78 x 12/55 mm. y 10/258 gr. Los sistemas operativos más empleados son el discoide y el kombewa (Tabla 16), seguidos de los métodos levallois con el índice más elevado del Complejo Inferior (19\%). Los núcleos de sílex son los más explotados $(70 \%$, frente al $45 \%$ de cuarcita).

En U IV hay 217 lascas, de las que 76 (35\%) están retocadas y 9 corresponden a cadenas operativas complejas $(4,2, \%)$ : tres lascas levallois preferenciales, tres levallois recurrentes, y tres kombewa. Sus dimensiones medias son: 36 x 33 x 12 mm. y sus intervalos: 13/82 x 13/84 x 2/46 $\mathrm{mm}$. Se ha reconocido cuatro productos de acondicionamiento de núcleo: una arista y tres flancos, mientras que sólo una lasca cuenta con morfología laminar. Las plataformas de percusión son las más trabajadas del Complejo Inferior, el lascado retocado presenta talones ligeramente más elaborados que la muestra general, hecho que se acentúa en los productos identificadores de cadenas operativas. Es la unidad con mayor índice de bulbos marcados, debido a la mayor presencia de sílex, materia prima cuyos bulbos son más prominentes (Tab. 17). De la observación de los contrabulbos conservados en los núcleos y de los bulbos del lascado, deducimos que los percutores empleados en la talla fueron fundamentalmente duros, utilizándose también los

\begin{tabular}{|c|c|c|c|c|c|c|c|c|}
\hline \multicolumn{3}{|c|}{ Córtex (N = 217) } & \multicolumn{3}{|c|}{ Talón $(\mathrm{N}=131)$} & \multicolumn{3}{|c|}{ Bulbo (N = 185) } \\
\hline Tipo & Total & $\%$ & Tipo & Total & $\%$ & Tipo & Total & $\%$ \\
\hline 1 & 12 & 5,5 & Liso & 85 & 65,4 & Marcados & 64 & 34,6 \\
\hline $2 A G$ & 2 & 0,9 & Cortical & 26 & 19,2 & Poco marcados & 81 & 43,8 \\
\hline $2 \mathrm{~A}$ & 19 & 8,7 & Diedro & 8 & 6,2 & No marcados & 13 & 7 \\
\hline $2 \mathrm{~B}$ & 11 & 5,1 & Facetado & 12 & 9,2 & No reconocibles & 27 & 14,6 \\
\hline $2 \mathrm{C}$ & 1 & 0,5 & & & & & & \\
\hline 3 & 172 & 79,3 & & & & & & \\
\hline
\end{tabular}

Tabla 17. Distribución del córtex, talón y bulbo en las lascas de la unidad IV.

T. P., 54, n. ${ }^{\circ} 1,1997$ 
blandos, en cualquier caso serían de peso y morfología adecuados, considerando el bajo índice de bulbos marcados y los escasos accidentes de talla [cinco fracturas Siret $(2,3 \%)$ ]. Casi una tercera parte (68 piezas) está fracturada, sus causas sólo se han reconocido en tres ocasiones: una posiblemente térmica y dos por flexión.

\subsubsection{Cadenas operativas mixtas}

La Unidad IV cuenta con 81 piezas retocadas (63 de sílex y 18 de cuarcita), cuyas dimensiones medias son 39 x 36 x $13 \mathrm{~mm}$. y sus intervalos 14/ 86 x 14/89 x 3/33 mm. Estos "utensilios" se han desarrollado fundamentalmente sobre lascas (77 ocasiones, en 3 sobre núcleo, y en una sobre chunk), que técnicamente apenas difieren de las del lascado global: similares índices de corticalidad, superficies de percusión incluso menos preparadas, el 7,4\% (6) corresponden a cadenas operativas complejas, etc., no hay por tanto una selección de la lasca soporte en función de la técnica de extracción. Sin embargo sí se aprecia una predilección por la materia prima (predomina el sílex con un $18 \%$ más que en el lascado), y por el tamaño (entre 3 y $4 \mathrm{~mm}$. de media superior). En los 81 útiles hay 111 lados retocados, retoque que es: fundamentalmente semiabrupto $(44,9 \%)$, siendo más común el abrupto $(37,7 \%)$ que el simple $(16,3 \%)$, el plano sólo se presenta en una ocasión; de morfología normal (sólo hay uno laminar); de amplitud generalmente intermedia $(45,9 \%)$, aunque están bien representados los profundos $(25,2 \%)$ y marginales $(26,1 \%)$, mientras que sólo hay dos escaleriformes; generalmente directo $(75,7 \%)$ aunque los inversos no son escasos $(20,7 \%)$, habiendo sólo uno bifacial; forma filos sobre todo convexos $(43,2 \%)$ pero también cóncavos $(27 \%)$ o rectos $(23,4 \%)$. El $30 \%$ muestra dos lados retocados, y sólo tres piezas tienen más de dos. El grupo predominante sigue siendo el II (48,5 de i.e.) (Fig. 4.2), al que sigue el IV (36,8 de i.e.), mientras el III no tiene representación (excepto una pieza donde se combina un denticulado convergente con un frente de raspador) (Tab. 18).

\subsubsection{Cadenas operativas de façonnage}

- Bifaces. Hay 15 (17,2 de i.e.), seis de cuarcita, ocho de sílex, y uno de caliza. Sus dimensio-

\begin{tabular}{|c|c|c|c|}
\hline Grupo & Clasificación & Total & $\%$ \\
\hline GRUPO II & $\begin{array}{l}\text { Limaces } \\
\text { Raederas simples } \\
\text { Raederas transversales } \\
\text { Raederas dobles } \\
\text { Raederas desviadas } \\
\text { Raederas sobre cara plana } \\
\text { Raederas alternantes } \\
\text { TOTAL }\end{array}$ & $\begin{array}{r}1 \\
12 \\
5 \\
8 \\
1 \\
1 \\
33\end{array}$ & $\begin{array}{r}1,2 \\
14,8 \\
6,2 \\
9,9 \\
1,2 \\
1,2 \\
6,2 \\
40,7\end{array}$ \\
\hline GRUPO III & $\begin{array}{l}\text { Denticulados } \\
\text { Puntas de Tayac } \\
\text { Afines a punta de Tayac } \\
\text { TOTAL }\end{array}$ & $\begin{array}{r}23 \\
\\
\\
26 \\
26\end{array}$ & $\begin{array}{r}28,4 \\
2,5 \\
1,2 \\
32,1\end{array}$ \\
\hline GRUPO IV & $\begin{array}{l}\text { Escotaduras } \\
\text { Becs } \\
\text { Lascas retocadas } \\
\text { TOTAL }\end{array}$ & $\begin{array}{r}2 \\
4 \\
19 \\
19\end{array}$ & $\begin{array}{r}2,5 \\
4,9 \\
16,0 \\
23,4\end{array}$ \\
\hline \multirow[t]{2}{*}{$\begin{array}{l}\text { "UTILES" } \\
\text { COMPUESTOS }\end{array}$} & Punta de Tayac+raspador & 1 & 1,2 \\
\hline & TOTAL & 81 & 100 \\
\hline
\end{tabular}

Tabla 18. Clasificación de las cadenas operativas mixtas de la unidad IV de Ambrona (Soria).

nes medias son: 137 x 79 x $40 \mathrm{~mm}$. y 446 gr. y sus intervalos $87 / 190$ x 42/105 x 20/68 mm. y 76/882 gr. Aunque en su formatización predominen los percutores duros, utilizándose exclusivamente en ocho piezas, el empleo de los blandos aumenta considerablemente respecto a las unidades inferiores ya que hay evidencias de su uso en siete casos (en tres exclusivamente y en cuatro se alternó con el duro). Predomina la talla amplia, completada con retoque en cinco bifaces, que proporciona siluetas normalizadas con aristas sinuosas o ligeramente sinuosas, y secciones biconvexas asimétricas. Con cuatro ejemplares es la unidad con mayor índice de bifaces planos, mientras que sólo hay uno parcial (Tab. 19; Fig. 4.3). Han proporcionado un mínimo de 327 lascas.

- Hendedores. Dos, uno de caliza y otro de sílex (2,3 de i.e.). De concepción técnica simple pero de formas regulares, uno es del tipo 0 y otro del II (Fig. 4.1).

- Triedros. Hay uno, siendo el único documentado en Ambrona, tecnológicamente muy elemental pero equilibrado. El desbastado corresponde a un sistema de explotación simple, integrándose en el tipo 3a (Querol y Santonja, 1979).

- Cantos trabajados. Sólo uno (1,1 de i.e.), de cuarcita, y formatizado con percutor duro, se sitúa en el tipo 3 de Querol. 


\begin{tabular}{|c|c|c|c|}
\hline Unidad IV & Tipos & Total & $\%$ \\
\hline \multirow[t]{2}{*}{ Planos } & $\begin{array}{l}\text { Ovalares } \\
\text { Limandes }\end{array}$ & $\begin{array}{l}2 \\
2\end{array}$ & $\begin{array}{l}13,3 \\
13,3\end{array}$ \\
\hline & Total planos & 4 & 26,7 \\
\hline \multirow[t]{2}{*}{ Espesos } & $\begin{array}{l}\text { Ficrones lanceolados } \\
\text { Amigdaloides cortos } \\
\text { Ovalares } \\
\text { Limandes }\end{array}$ & $\begin{array}{l}1 \\
1 \\
1 \\
3\end{array}$ & $\begin{array}{r}6,7 \\
6,7 \\
6,7 \\
20,0\end{array}$ \\
\hline & Total espesos & 6 & 40 \\
\hline \multicolumn{2}{|c|}{ Filo transversal } & 2 & 13,3 \\
\hline Parciales & Limandes espesos & 1 & 6,7 \\
\hline \multicolumn{2}{|c|}{ Abbevillenses } & 1 & 6,7 \\
\hline Diversos & Bifaces con dorso & 1 & 6,7 \\
\hline Total & & 15 & 100 \\
\hline
\end{tabular}

Tabla 19. Siluetas de los bifaces de la unidad IV de Ambrona.

\subsubsection{Conclusiones}

La muestra adolece de los problemas planteados en las unidades inferiores: bajísima densidad y fragmentariedad en las cadenas operativas. Las 217 lascas son escasas si consideramos que en los núcleos se han estimado un mínimo de 142 extracciones, que éstos aparecen mayoritariamente muy desbastados, que algunos chunks pueden ser núcleos supra-explotados, y que los elementos de las cadenas operativas de façonnage también han proporcionado lascas (más de 327). Los 43 debris clasificados son insuficientes para una muestra en la que hay 76 piezas retocadas y en la que casi la mitad de los núcleos identificables están agotados. Por su parte los productos identificadores de cadenas operativas contrastan cualitativa y cuantitativamente con sus núcleos correspondientes. En el lascado están ausentes los tipos de primer orden correspondientes al descortezado, que puede deberse a que los núcleos fueran desprovistos de este atributo fuera del yacimiento, o al menos en alguna zona no conservada o excavada. A diferencia de U II y U III la distribución de los talones y materias primas de los negativos de los núcleos contrastan con los del lascado, por lo que no lo podemos utilizar como argumento para asegurar la pertenencia de todos los elementos a una misma población. No obstante el carácter tecnológico global de la industria (aprovechamiento muy elevado de la materia prima, percutores empleados, etc.) aboga por este planteamiento. En las de façonnage se agudizan los problemas planteados indicados para las unidades precedentes: no se ha podido adscribir ni una sola lasca a ningún bifaz, y tampoco se han observado núcleos que puedan haber proporcionado lascas aptas como soporte de hendedores, por lo que es posible que se introdujeran ya formatizados sus elementos característicos.

\subsection{Complejo Superior}

\subsubsection{Nivel VA}

El nivel VA, formado por depósitos aluvia-les, está compuesto por margas arenosas $(\mathrm{de} 90 \mathrm{~cm}$. de espesor máximo; Butzer, 1965). La muestra general contiene 991 piezas, de las que el 83,9\% de la serie se puede adscribir a cadenas operativas de débitage, el $15 \%$ a cadenas operativas mixtas, y sólo el $1 \%$ a las de façonnage (Tab. 20). En las materias primas domina el grupo del sílex $(52,6 \%)$, seguida de la cuarcita $(43 \%)$, y con un índice muy bajo la caliza $(4,4 \%)$. Aunque no es una muestra muy alterada destaca la frecuente desilicificación del sílex $(71,8 \%)$, y el redondeamiento observado en el $34,2 \%$ de la muestra, básicamente ligero.

\begin{tabular}{|c|c|c|}
\hline Categorías & Total & $\%$ \\
\hline $\begin{array}{l}\text { Núcleos } \\
\text { Lascas } \\
\text { Debris } \\
\text { Chunks } \\
\end{array}$ & $\begin{array}{r}20 \\
539 \\
221 \\
51 \\
\end{array}$ & $\begin{array}{r}2,1 \\
54,4 \\
22,3 \\
5,1 \\
\end{array}$ \\
\hline Total c.o.d. & 831 & 83,9 \\
\hline Útiles & 149 & 15 \\
\hline Total c.o.m. & 149 & 15 \\
\hline $\begin{array}{l}\text { Bifaces } \\
\text { Hendedores } \\
\text { Triedros } \\
\text { C.T. }\end{array}$ & $\begin{array}{l}8 \\
2 \\
0 \\
0\end{array}$ & $\begin{array}{r}0,8 \\
0,2 \\
0 \\
0\end{array}$ \\
\hline Total c.o.f. & 10 & 1 \\
\hline Percutores & 1 & 0,1 \\
\hline Total & 991 & 100 \\
\hline
\end{tabular}

Tabla 20. Distribución por categorías del nivel VA de Ambrona (Soria). 


\subsubsection{Cadenas operativas de débitage}

El nivel VA cuenta con 24 núcleos ( 16 de sílex, 7 de cuarcita y 1 de caliza), seis de ellos retocados. Sus dimensiones medias son: 53 x $40 \times 20$ mm. y 60 gr., y sus intervalos: 29/122 x 10/97 x $10 / 36$ y 8/446 gr. de peso. Las cadenas operativas más relevantes son las levallois seguidas de las discoides (Fig. 5.1), juntas superan el $70 \%$ de la muestra (Tab. 21), son las que presentan mayor grado de explotación, que es superior en el sílex que en la cuarcita, lo que podría relacionarse con una mayor escasez de dicha materia prima. Los núcleos reflejan al menos 240 extracciones.

De las 681 lascas, 143 están retocadas $(20,9 \%)$ y la mitad fracturadas. Sus dimensiones medias son: 34 x 32 x $10 \mathrm{~mm}$. y sus intervalos: $8 / 92 \times 10 / 75 \times 1 / 35 \mathrm{~mm}$. La materia prima dominante es el sílex $(50,5 \%)$, seguida de la cuarcita $(46,2 \%)$ y la caliza $(3,1 \%)$. La serie es acortical en el $78,8 \%$ de los casos, y cuando presenta córtex ocupa menos de un tercio del anverso
(Tab. 22). Como productos de acondicionamiento sólo se han distinguido dos flancos de núcleo. Entre las superficies de percusión predominan las no preparadas. Los bulbos están poco o nada mar-cados $(74,3 \%)$, sugiriendo el empleo en la talla de percutores poco pesados (Tabla 22). En 25 lascas se ha podido identificar la cadena operativa a la que pertenecen: 7 a las levallois de extraccion preferencial, 13 levallois recurrentes, 1 discoides, 3 kombewa, y 4 bifaciales (lascas de avivado de bifaz), además de 1 punta seudolevallois.

\subsubsection{Cadenas operativas mixtas (c.o.m.)}

El nivel VA cuenta con 149 piezas retocadas. Los soportes más utilizados son las lascas (96\%), aunque también se documentan núcleos o chunks (4\%), y la materia prima predominante el sílex $(73,6 \%)$. Sus dimensiones medias son: $48 \times 43 \times$ $13 \mathrm{~mm}$. y sus intervalos: 20/98 x 10/125 x 5/34

\begin{tabular}{|c|c|c|c|c|c|c|}
\hline Cadenas operativas de débitage & Núcleos & Total & $\%$ & Productos & Total & $\%$ \\
\hline $\begin{array}{l}\text { Muy elementales } \\
\text { Elementales } \\
\text { Piramidales } \\
\text { Multifaciales } \\
\text { Bifaciales } \\
\text { Discoides } \\
\text { Levallois } \\
\text { Kombewa }\end{array}$ & $\begin{array}{l}\text { Grupo I } \\
\text { Grupo II } \\
\text { Grupo III } \\
\text { Grupo IV } \\
\text { Grupo V } \\
\text { Grupo VI } \\
\text { Grupo VII } \\
\text { Grupo VIII }\end{array}$ & $\begin{array}{l}1 \\
0 \\
0 \\
0 \\
2 \\
5 \\
6 \\
1\end{array}$ & $\begin{array}{r}6,7 \\
0 \\
0 \\
0 \\
13,3 \\
33,3 \\
39,9 \\
6,7\end{array}$ & $\begin{array}{l}\text { Irreconocibles } \\
\text { Irreconocibles } \\
\text { Irreconocibles } \\
\text { Irreconocibles } \\
\text { Irreconocibles } \\
\text { Lascas discoides } \\
\text { Lascas levallois } \\
\text { Lascas kombewa }\end{array}$ & $\begin{array}{l}- \\
\overline{-} \\
\overline{-} \\
- \\
2 \\
20 \\
3\end{array}$ & $\begin{array}{l}- \\
\overline{-} \\
- \\
\overline{0} \\
0,3 \\
0,4\end{array}$ \\
\hline & Total & 15 & 100 & Total & 681 & \\
\hline & $\begin{array}{l}\text { Grupo IX } \\
\text { Fragmentos }\end{array}$ & $\begin{array}{l}8 \\
1\end{array}$ & & & & \\
\hline & Total & 24 & & & & \\
\hline
\end{tabular}

Tabla 21. Distribución de las cadenas operativas de débitage del nivel VA de Ambrona (Soria).

\begin{tabular}{|c|c|c|c|c|c|c|c|c|}
\hline \multicolumn{3}{|c|}{ Córtex $(\mathbf{N}=680)$} & \multicolumn{3}{|c|}{ Talón $(\mathrm{N}=384)$} & \multicolumn{3}{|c|}{ Bulbo $(\mathrm{N}=499)$} \\
\hline Tipo & Total & $\%$ & Tipo & Total & $\%$ & Tipo & Total & $\%$ \\
\hline 1 & 16 & 2,3 & Liso & 275 & 71,7 & Marcados & 78 & 15,6 \\
\hline $2 \mathrm{AG}$ & 25 & 3,7 & Cortical & 62 & 16,1 & Poco marcados & 31 & 6,2 \\
\hline $2 \mathrm{~A}$ & 86 & 12,6 & Diedro & 22 & 5,7 & No marcados & 342 & 68,5 \\
\hline $2 \mathrm{~B}$ & 8 & 1,2 & Facetado & 25 & 6,5 & No reconocibles & 48 & 9,7 \\
\hline $2 \mathrm{C}$ & 8 & 1,2 & & & & & & \\
\hline 3 & 537 & 79 & & & & & & \\
\hline
\end{tabular}

Tabla 22. Distribución del córtex, talón y bulbo del lascado del nivel VA de Ambrona (Soria). 

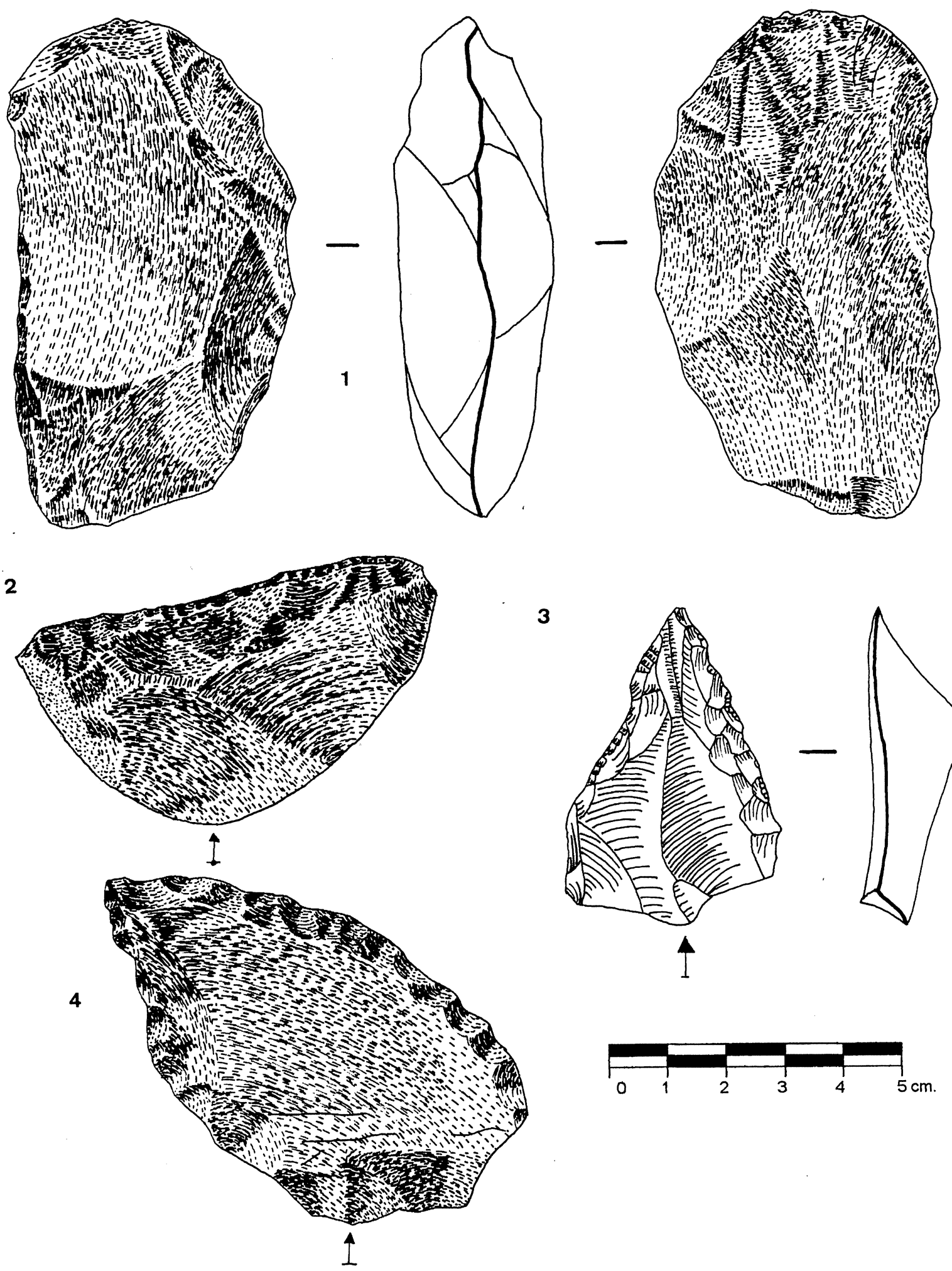

3
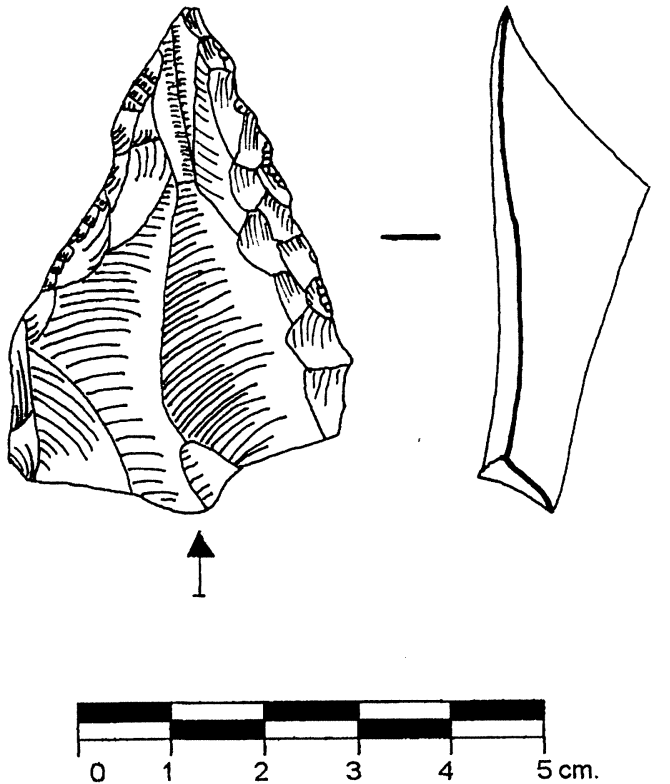

Fig. 5. Nivel VA de Ambrona (Soria). 1. Núcleo del grupo VII (levallois de extracción preferencial). 2. Raedera transversal. 3. Punta musteriense. 4. Punta de Tayac.

T. P., 54, n. $^{\circ} 1,1997$ 
mm., las medias de la longitud son mayores que las del lascado en $10 \mathrm{~mm}$., lo que hace pensar en una selección de las piezas más grandes para retocar. Las características técnicas de las lascas soporte no difieren de las del lascado general: bajo índice de corticalidad, superficies de percusión poco elaboradas y similar proporción de productos identificadores de cadenas operativas. Tipológicamente domina el grupo de las raederas $(61,7 \%)$, al que siguen los denticulados $(18,8 \%)$, mientras el grupo III está escasamente representado (1,3\%) (Tab. 23; Fig. 5.2,3 y 4). El retoque es fundamentalmente simple $(62,6 \%)$, aunque está bien documentado el semiabrupto $(29,8 \%)$ y el abrupto $(7,4 \%)$, éstos dos últimos se han observado con frecuencia en denticulados y puntas de Tayac; el 15,1\% tiene dos lados retocados y sólo una pieza posee más de dos $(0,6 \%)$; es directo en cuanto a su dirección $(89,2 \%)$, y forma filos convexos o rectos $(55,4 \%$ y $24,7 \%$ respectivamente, el resto son cóncavos).

\subsubsection{Cadenas operativas de façonnage (c.o.f.)}

- Bifaces. Ocho piezas ( 2 de cuarcita, 3 de caliza y 3 de sílex) que proporcionaron un mínimo de 195 lascas. Sólo los protolimandes muestran retoque secundario. Sus dimensiones medias son: 105 x 62 x $33 \mathrm{~mm}$. y 243 gr. y sus intervalos: 65/ 150 x 31/92 x 16/47 mm. y 20/510 gr. Los soportes más frecuentes son los cantos globulosos (cuatro). Cinco cuentan con córtex que ocupa menos de un tercio de su volumen. Las formas más frecuentes son las amigdaloides, ovalares y limandes (Tab. 24). Son de siluetas equilibradas y simétricas, con aristas medianamente sinuosas, y destaca el empleo del percutor blando tanto en la formatización como en el retoque.

- Hendedores. Sólo hay dos $(0,2 \%)$ de morfología equilibrada y técnica simple (uno atípico y otro tipo VI). Uno formatizado con percutor duro, mientras que en el otro (tipo VI) se empleó percutor poco pesado en el retoque del filo.

\subsubsection{Conclusiones}

La composición general de la serie sugiere la existencia de cadenas operativas completas, como corrobora que: hay 700 lascas reales frente a las

\begin{tabular}{|c|c|c|c|}
\hline Grupo & Clasificación & Total & $\%$ \\
\hline GRUPO II & $\begin{array}{l}\text { Puntas musterienses } \\
\text { Raederas simples } \\
\text { Raederas transversales } \\
\text { Raederas dobles } \\
\text { Raederas convergentes } \\
\text { Raederas desviadas } \\
\text { Raederas sobre cara plana } \\
\text { Raedera retoque abrupto } \\
\text { TOTAL }\end{array}$ & \begin{tabular}{r|r}
2 & \\
55 & \\
16 & \\
7 & \\
2 & \\
4 & \\
7 & \\
1 &
\end{tabular} & $\begin{array}{r}1,3 \\
36,8 \\
10,7 \\
4,7 \\
1,3 \\
2,7 \\
4,7 \\
0,7 \\
62,9\end{array}$ \\
\hline GRUPO III & $\begin{array}{l}\text { Raspadores atípicos } \\
\text { TOTAL }\end{array}$ & 1 & $0,7^{0,7}$ \\
\hline GRUPO IV & $\begin{array}{l}\text { Denticulados } \\
\text { Puntas de Tayac } \\
\text { TOTAL }\end{array}$ & \begin{tabular}{rr|} 
& 25 \\
& 3 \\
28 &
\end{tabular} & $\begin{array}{r}16,8 \\
18,8\end{array}$ \\
\hline GRUPO OTROS & $\begin{array}{l}\text { Escotaduras } \\
\text { Becs } \\
\text { Lascas retocadas } \\
\text { Diversos } \\
\text { TOTAL }\end{array}$ & $\begin{array}{rr} & 5 \\
& 1 \\
& 14 \\
22 & 2\end{array}$ & $\begin{array}{r}3,4 \\
0,7 \\
9,4 \\
1,3 \\
14,8\end{array}$ \\
\hline $\begin{array}{l}\text { "ÚTILES" } \\
\text { COMPUESTOS }\end{array}$ & $\begin{array}{l}\text { Raedera simple+denticulad } \\
\text { Raedera simple+escotadura } \\
\text { Raedera simple+raspador }+ \\
\text { denticulado } \\
\text { Escotadura+denticulado }\end{array}$ & $\begin{array}{l}1 \\
1 \\
1 \\
1\end{array}$ & $\begin{array}{l}0,7 \\
0,7 \\
0,7 \\
0,7\end{array}$ \\
\hline & TOTAL & 149 & 100 \\
\hline
\end{tabular}

Tabla 23. Clasificación de las cadenas operativas mixtas del nivel VA de Ambrona (Soria).

435 extracciones estimadas para núcleos y bifaces; la materia prima estimada para los negativos de los núcleos y la del lascado real es similar, al igual que lo son las superficies de percusión y el tipo de percutor empleado, confirmando que ambas muestras pertenecen a una misma población; en las c.o. de façonnage, y concretamente en las

\begin{tabular}{|c|c|c|c|}
\hline Nivel VA & Siluetas & Total & $\%$ \\
\hline \multirow[t]{2}{*}{ Espesos } & $\begin{array}{l}\text { Ovalares } \\
\text { Protolimandes }\end{array}$ & $\begin{array}{l}2 \\
2\end{array}$ & $\begin{array}{l}25 \\
25\end{array}$ \\
\hline & Total espesos & 4 & 50 \\
\hline \multirow[t]{2}{*}{ Parciales } & $\begin{array}{l}\text { Lanceolado } \\
\text { Amigdaloides }\end{array}$ & $\begin{array}{l}1 \\
2 \\
\end{array}$ & $\begin{array}{r}12,5 \\
25 \\
\end{array}$ \\
\hline & Total parciales & 3 & 37,5 \\
\hline \multicolumn{2}{|c|}{ Con dorso } & 1 & 12,5 \\
\hline Total & & 8 & 100 \\
\hline
\end{tabular}

Tabla 24. Siluetas de los bifaces del nivel VA de Ambrona. 
bifaciales, se han documentado cinco lascas de bifaz frente a la existencia de ocho bifaces.

\subsubsection{Nivel VB}

El nivel VB está formado por las denominadas gravas C (Butzer, 1965), facies que se documenta en las márgenes del yacimiento y que se constituyó deposicionalmente por episodios fluviales intermitentes. La serie lítica comprende 883 piezas, de las que 743 corresponden a cadenas operativas de débitage $(84,1 \%), 129$ a mixtas $(14,7 \%)$, y $9(1 \%)$, a cadenas operativas de façonnage (Tab. 25). En las materias primas domina el grupo del sílex con el 58,2\% (diferenciándose ópalos y chert), seguido de la cuarcita $(38,4 \%)$, y en menor proporción de la caliza $(3,4 \%)$. Las aristas están menos «redondeadas» que en el nivel anterior $(30,3 \%)$. La desilicificación afecta al 57,6\% del sílex, y sólo el 1,2\% de la muestra está patinada.

\subsubsection{Cadenas operativas de débitage}

Hay 24 núcleos (17 de sílex, 6 de cuarcita y 1 de caliza), de los que 3 están retocados, con unas dimensiones medias de $58 \times 40 \times 23 \mathrm{~mm}$. y 50 gr. e intervalos de 28/81 x 22/64 x 14/31 mm. y 15/150 gr. En la identificación de cadenas operativas resulta reveladora la primacía de las discoides y levallois (Tab. 26), que coinciden con los que mayor grado de explotación presentan. De estos 24 núcleos se obtuvieron un mínimo de 215 lascas.

\begin{tabular}{|c|c|c|}
\hline Categorías & Total & $\%$ \\
\hline $\begin{array}{l}\text { Núcleos } \\
\text { Lascas } \\
\text { Debris } \\
\text { Chunks } \\
\end{array}$ & $\begin{array}{r}21 \\
501 \\
187 \\
34 \\
\end{array}$ & $\begin{array}{r}2,4 \\
56,7 \\
21,2 \\
3,8 \\
\end{array}$ \\
\hline Total c.o.d. & 743 & 84,1 \\
\hline Útiles & 129 & 14,7 \\
\hline Total c.o.m. & 129 & 14,7 \\
\hline $\begin{array}{l}\text { Bifaces } \\
\text { Hendedores } \\
\text { Triedros } \\
\text { C.T. }\end{array}$ & $\begin{array}{l}9 \\
0 \\
0 \\
0\end{array}$ & $\begin{array}{l}1 \\
0 \\
0 \\
0\end{array}$ \\
\hline Total c.o.f. & 9 & 1 \\
\hline Percutores & 2 & 0,2 \\
\hline Total & 883 & 100 \\
\hline
\end{tabular}

Tabla 25. Distribución por categorías del nivel VB de Ambrona (Soria).

De las 626 lascas 125 están retocadas $(20 \%)$ y 325 fracturadas $(51,9 \%)$. Prima, al igual que en la muestra general, el empleo del sílex $(57,7 \%)$ sobre la cuarcita y caliza $(39,6 \%$ y $2,7 \%)$. Sus dimensiones medias son: $35 \times 32 \times 10 \mathrm{~mm}$. y sus intervalos: $11 / 89 \times 9 / 79 \times 2 / 34 \mathrm{~mm}$. Se ha reconocido un flanco de núcleo y una lasca con morfología laminar. El lascado es predominantemente acortical, y las superficies de percusión elaboradas son escasas (Tab. 27). El predominio generalizado en la talla del percutor blando, o poco pesado, viene marcado por el elevado porcentaje de bulbos poco o nada marcados. En 24 casos hemos identificado sus cadenas operativas:

\begin{tabular}{|l|l|r|r|r|r|r|}
\hline Cadenas operativas de débitage & Núcleos & Total & $\boldsymbol{\%}$ & Productos & Total & \% \\
\hline Muy elementales & Grupo I & 1 & 5,6 & Irreconocibles & - & - \\
Elementales & Grupo II & 0 & 0 & Irreconocibles & - & - \\
Piramidales & Grupo III & 3 & 16,6 & Irreconocibles & - & - \\
Multifaciales & Grupo IV & 1 & 5,6 & Irreconocibles & - & - \\
Bifaciales & Grupo V & 1 & 5,6 & Irreconocibles & - & - \\
Discoides & Grupo VI & 4 & 22,2 & Lascas discoides & 3 & 0,5 \\
Levallois & Grupo VII & 8 & 44,4 & Lascas levallois & 21 & 3,3 \\
Kombewa & Grupo VIII & 0 & 0 & Lascas kombewa & 0 & 0 \\
\hline & Total & $\mathbf{1 8}$ & $\mathbf{1 0 0}$ & Total & $\mathbf{6 2 6}$ & \\
\hline & Grupo IX & 6 & & & & \\
\end{tabular}

Tabla 26. Distribución de las cadenas operativas de débitage del nivel VB de Ambrona (Soria).

T. P., 54, n. $^{\circ} 1,1997$ 


\begin{tabular}{|c|c|c|c|c|c|c|c|c|}
\hline \multicolumn{3}{|c|}{ Córtex (N = 680) } & \multicolumn{3}{|c|}{ Talón $(\mathrm{N}=384)$} & \multicolumn{3}{|c|}{ Bulbo $(N=499)$} \\
\hline Tipo & Total & $\%$ & Tipo & Total & $\%$ & Tipo & Total & $\%$ \\
\hline 1 & 19 & 3,0 & Liso & 251 & 77 & Marcados & 72 & 16,6 \\
\hline $2 \mathrm{AG}$ & 23 & 3,7 & Cortical & 44 & 13,5 & Poco marcados & 279 & 64,4 \\
\hline $2 \mathrm{~A}$ & 57 & 9,1 & Diedro & 16 & 4,9 & No marcados & 42 & 9,7 \\
\hline $2 \mathrm{~B}$ & 10 & 1,6 & Facetado & 16 & 4,6 & No reconocibles & 40 & 9,3 \\
\hline $2 \mathrm{C}$ & 7 & 1,1 & & & & & & \\
\hline 3 & 510 & 81,5 & & & & & & \\
\hline
\end{tabular}

Tabla 27. Distribución del córtex, talón y bulbo del lascado del nivel VB de Ambrona (Soria).

14 lascas levallois preferenciales, 7 levallois recurrentes, y 3 puntas seudolevallois.

\subsubsection{Cadenas operativas mixtas}

VB cuenta con 129 utensilios de los que el $72,1 \%$ son de sílex y el $27,9 \%$ restante de cuarcita. Sus dimensiones medias son: 49 x 41 x $13 \mathrm{~mm}$. y sus intervalos: 21/117 x 19/76 x 3/29 mm., superando al lascado en 12 × $8 \mathrm{~mm}$. de media. Se han seleccionado en el $96,9 \%$ de los casos lascas como soporte (con características técnicas similares a las del lascado global), y núcleos o chunks en el $2,3 \%$ restante. Predomina el grupo de las raederas, donde destacan las simples, seguidas del grupo de los denticulados (Tab. 28; Fig. 6). En el retoque prevalece el tipo simple y plano $(56,8 \%)$, y en menor medida el semiabrupto $(28,7 \%)$ y abrupto $(14,4 \%)$, en general es directo $(86,2 \%)$, aunque están representadas las restantes categorías (inversos $11,8 \%$, bifaciales $1,3 \%$ y alternantes $0,7 \%$ ). Algo más de una cuarta parte $(27 \%)$ tiene dos lados retocados y sólo el $0,7 \%$ posee más de dos.

\subsubsection{Cadenas operativas de façonnage}

Sólo cuenta con nueve bifaces que representan el $1 \%$ de la serie global, 4 son de sílex, 3 de caliza y 2 de cuarcita. Los soportes más frecuentes son lascas $(33,3 \%)$ y cantos rodados $(22,2 \%)$, en sílex y cuarcita respectivamente. Sus dimensiones medias son: 93 x 57 x 35 mm. y 202 gr. de peso, y sus intervalos: $70 / 135$ x 26/7 x 21/59 mm. y 39/450 gr. Las formas más comunes son las amigdaloides y ovalares (Tab. 29), con siluetas poco simétricas de aristas regularmente sinuosas, prevaleciendo en su formatización el percutor blando en al menos 6 piezas (uno exhibe retoque secundario). De los nueve ejemplares se obtuvieron un mínimo de 122 lascas.

\subsubsection{Conclusiones}

La distribución general de la industria sugiere la existencia de cadenas operativas completas como confirma que en los núcleos y en los bifa-

\begin{tabular}{|c|c|c|c|}
\hline Grupo & Clasificación & Total & $\%$ \\
\hline GRUPO II & $\begin{array}{l}\text { Limaces } \\
\text { Raederas simples } \\
\text { Raederas transversales } \\
\text { Raederas dobles } \\
\text { Raederas convergentes } \\
\text { Raederas desviadas } \\
\text { Raederas sobre cara plana } \\
\text { Raedera alternas } \\
\text { TOTAL }\end{array}$ & $\begin{array}{l}92 \\
92\end{array}$ & $\begin{array}{r}0,8 \\
41,9 \\
7,8 \\
6,2 \\
3,1 \\
3,1 \\
6,2 \\
2,2 \\
71,3\end{array}$ \\
\hline GRUPO IV & $\begin{array}{l}\text { Denticulados } \\
\text { Puntas de Tayac } \\
\text { TOTAL }\end{array}$ & $\begin{array}{r}20 \\
\quad 1 \\
21 \quad\end{array}$ & $\begin{array}{r}15,5 \\
\\
16,3\end{array}$ \\
\hline GRUPO OTROS & $\begin{array}{l}\text { Lascas retocadas } \\
\text { Rabot } \\
\text { Diversos } \\
\text { TOTAL }\end{array}$ & $\begin{array}{l}8 \\
1 \\
2\end{array}$ & $\begin{array}{r}6,2 \\
0,8 \\
\\
1,5 \\
8,5\end{array}$ \\
\hline $\begin{array}{l}\text { "ÚTILES" } \\
\text { COMPUESTOS }\end{array}$ & $\begin{array}{l}\text { Raedera simple+denticulado } \\
\text { Raedera simple+raspador+ } \\
\text { +denticulado } \\
\text { Denticulado+raedera sim- } \\
\text { ple+escotadura } \\
\text { Denticulado+escotadura }\end{array}$ & $\begin{array}{l}2 \\
1 \\
1 \\
1\end{array}$ & $\begin{array}{l}1,5 \\
0,8 \\
0,8 \\
0,8 \\
\end{array}$ \\
\hline & TOTAL & 129 & 100 \\
\hline
\end{tabular}

Tabla 28. Clasificación de las cadenas operativas mixtas del nivel VB de Ambrona. 

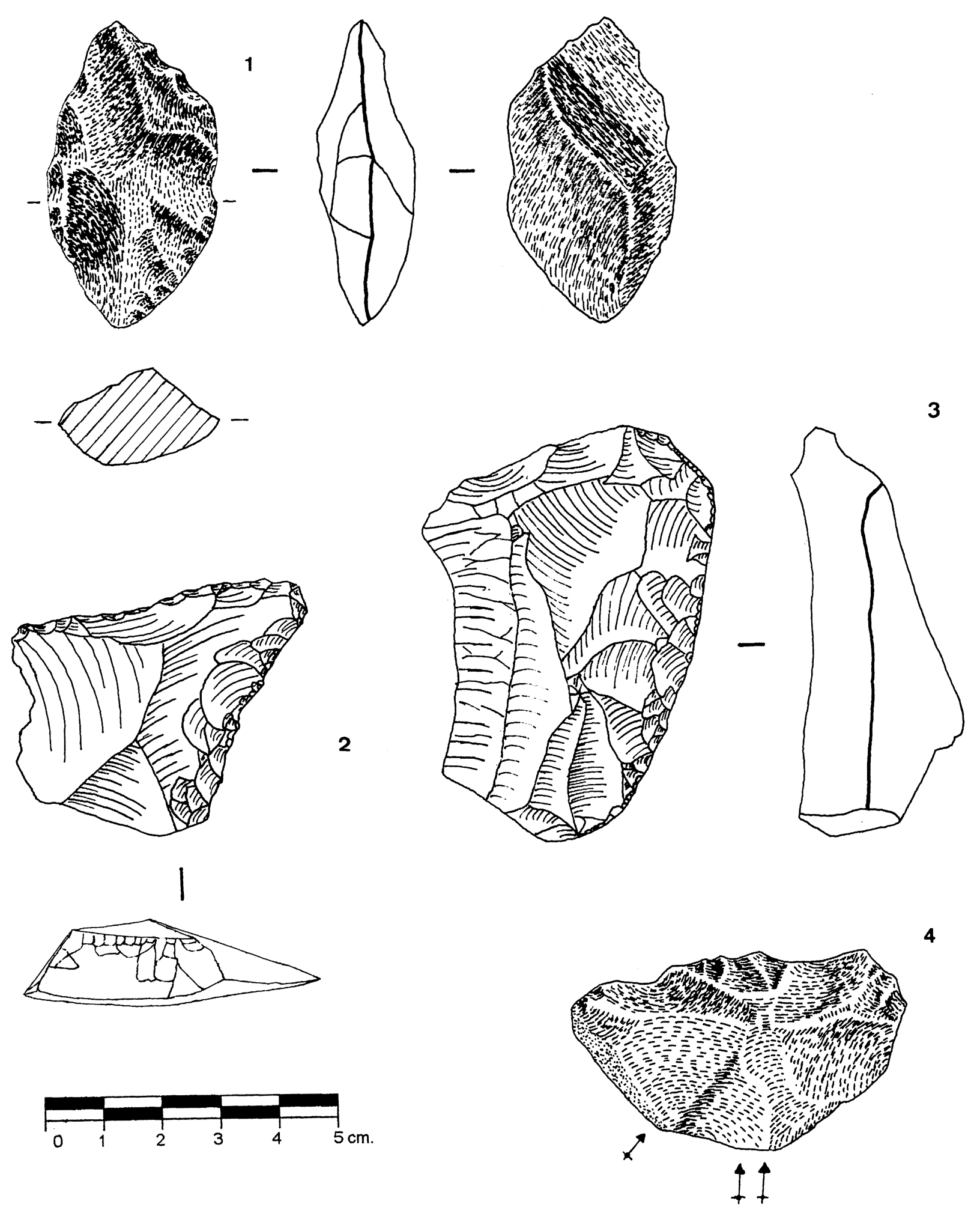

Fig. 6. Nivel VB de Ambrona (Soria). 1. Limace. 2. Raedera simple. 3. Raedera desviada sobre lasca levallois de extracción preferencial. 4. Denticulado.

T. P., 54, n. ${ }^{\circ} 1,1997$ 


\begin{tabular}{|c|c|c|c|}
\hline Nivel VA & Siluetas & Total & $\%$ \\
\hline Planos & Cordiformes & 1 & 11,1 \\
\hline \multirow[t]{4}{*}{ Espesos } & Amigdaloides & 1 & 11,1 \\
\hline & Ovalares & 2 & 22,2 \\
\hline & Protolimande & 1 & 11,1 \\
\hline & Total espesos & 4 & 44,4 \\
\hline \multirow[t]{2}{*}{ Parciales } & Amigdaloides & 2 & 22,2 \\
\hline & Total parciales & 2 & 22,2 \\
\hline \multicolumn{2}{|c|}{ Abbevillenses } & 1 & 11,1 \\
\hline \multicolumn{2}{|c|}{ Con dorso } & 1 & 11,1 \\
\hline Total & & 9 & 100 \\
\hline
\end{tabular}

Tabla 29. Siluetas de los bifaces del nivel VB de Ambrona.

ces hayamos estimado 337 extracciones, cifra inferior a las 501 lascas reales, y que haya veintiuna lascas levallois frente a ocho núcleos levallois, abogando por la existencia de varias series de acondicionamiento en estos núcleos. La escasez de lascas corticales puede interpretarse como que la materia prima se introduce con el proceso de descortezado iniciado, hecho que se acentúa notablemente en el sílex.

\subsection{Comparación entre el Complejo Inferior y Superior}

El primer elemento a considerar es la fragmentariedad de las cadenas operativas del Complejo Inferior, mientras que en el Superior se muestran ciertamente más completas (Fig. 7). La distribución de las materias primas no es muy disonante, aunque el sílex predomina con mayor margen sobre la cuarcita en el Superior, donde destaca la total ausencia de cuarzo.

En las cadenas operativas de débitage del Complejo Superior hay una considerable mayor presencia de las más progresivas (en base a los núcleos), sobre todo respecto a las levallois (grupo VII), siendo destacable la escasa representación de las kombewa (grupo VIII), que están totalmente ausentes en VB, mientras que en U IV, la unidad del Complejo Inferior con las cadenas operativas menos elementales (Fig. 8), son, junto con las discoides, las más usuales. En el lascado las dimensiones y la corticalidad de ambos com- plejos son afines, mientras que los talones, poco elaborados en ambas muestras, se presentan en el Superior ligeramente menos preparados que en $\mathrm{U}$ IV (5), donde además los bulbos sugieren que el percutor blando fue más empleado.

En la formatización de las cadenas operativas mixtas se seleccionaron los mismos soportes en ambas series, generalmente lascas que técnicamente sólo difieren de las del lascado global en las dimensiones, que son superiores, diferencia que se acentúa en el Complejo Superior donde se produce una mayor selección por el tamaño. $\mathrm{La}$ caracterización global del retoque es claramente más estandarizada y regular en el Complejo Superior, en el que las formas simples, profundas y directas son las predominantes, mientras que en el Inferior las proporciones están menos polarizadas, repartiéndose con mayor equilibrio entre las distintas categorías propuestas. Tipológicamente las cadenas operativas mixtas del Complejo Superior son claramente menos variadas, centrándose entorno al Grupo II, cuyas raederas presentan tipos mejor definidos y más progresivos, mientras que el Grupo III está prácticamente ausente (en contraste con U. III), y los denticulados y el grupo Otros están menos representados que en el Complejo Inferior.

En las cadenas operativas de façonnage las discrepancias son considerables: en el Complejo Superior destaca en primer lugar la baja representación que alcanzan ( $1 \%$ frente a $3,4 \%$ y $5,5 \%$ para U III y U IV), y en segundo la total ausencia de Cantos Trabajados y la exigua muestra de hendedores (sólo 2 pertenecientes a VA), aunque se trata de tipos más equilibrados que los del Inferior. En los bifaces de este Complejo, además de su baja proporción, cabe señalar que: dimensionalmente sea una muestra más homogénea y reducida que la del Complejo Inferior; sus siluetas están polarizadas en torno a las amigdaloides y ovalares, siendo las del Inferior mucho más variadas; los tipos planos están prácticamente ausentes en VA y VB, mientras alcanzan cierta importancia en U IV (una cuarta parte); las siluetas se regularizan mediante retoque con mayor frecuencia y el percutor blando también se evidencia con mayor solidez.

(5) 4,4 y 9,2 de facetado estricto para las Unidades III y $\mathrm{U}$. IV frente a 6,5 y 4,6 para los niveles VA y VB, mientras que el facetado amplio es de 10,3, 15,4, 12,2 y 9,5 siguiendo el mismo orden. 


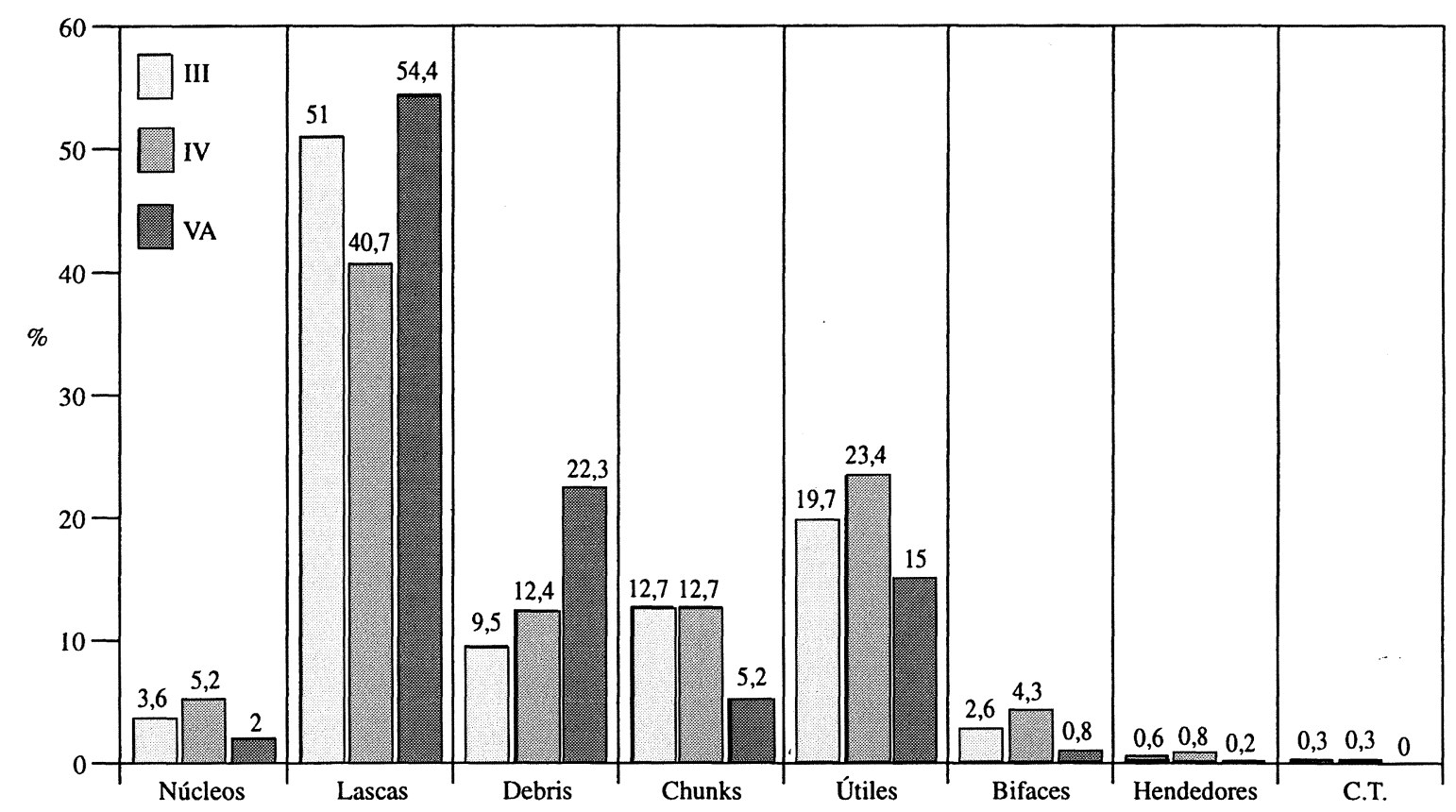

Fig. 7. Industria de los Complejos Superior e Inferior de Ambrona (Soria).

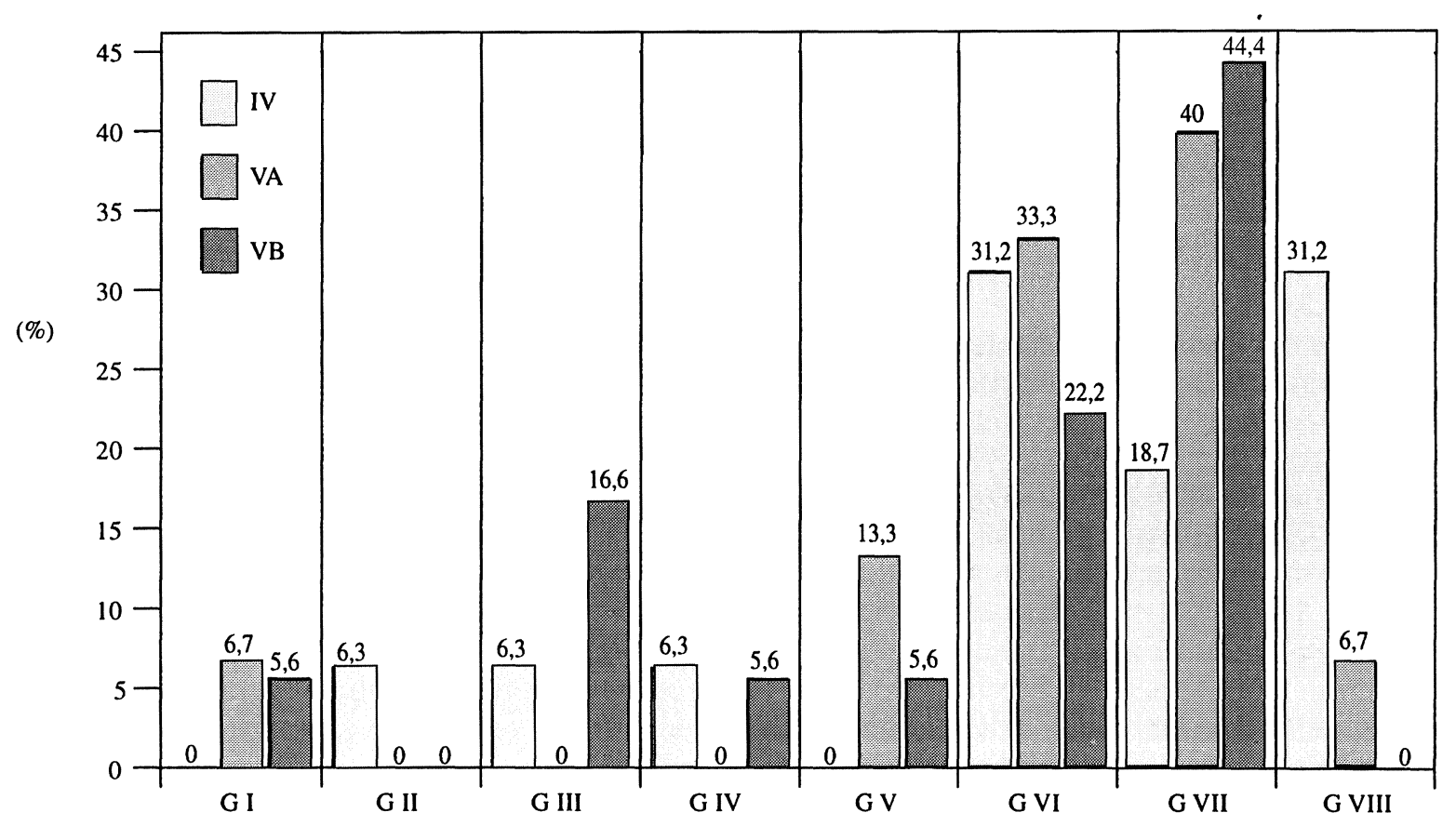

Fig. 8. Distribución de los núcleos del nivel más progresivo del Complejo Inferior, contrastado con los del Superior de Ambrona (Soria).

T. P., 54, n. ${ }^{\circ} 1,1997$ 
Sintetizando, la primera diferencia característica es la fragmentariedad de las cadenas operativas del Complejo Inferior, frente a su presencia más completa en el Superior. Partiendo de similares materias primas en ambos complejos, la serie del Superior presenta elementos claramente más progresivos y elaborados (con mayor evidencia del empleo del percutor blando), cadenas operativas de débitage conceptualmente más complejas, cadenas operativas mixtas más estandarizadas y regulares, exigua proporción de cadenas operativas de façonnage, con bifaces menos variados y formatizados, y hendedores, aunque escasos, más simétricos, realizados con mayor ahorro de gestos técnicos.

\section{CONTEXTUALIZACIÓN DE AMBRONA EN EL ACHELENSE PENINSULAR}

En este apartado comparamos la industria de Ambrona con la de los yacimientos en estratigrafía atribuidos al Pleistoceno medio en la Península Ibérica cuya documentación cumpla unos requisitos mínimos bajo los que podamos establecer unos parámetros de contraste: El Aculadero (Querol y Santonja, 1983), Los Llanos -San Quirce del Río Pisuerga (Arnaiz, 1990; Arnaiz y Cuesta, 1994)-, Pinedo (Querol y Santonja, 1979), La Maya II (Santonja, 1984b), el Sartalejo (Santonja, 1985), Áridos I (Santonja et alii, 1980), Torralba (Ortega, 1994), Solana del Zamborino (Botella, 1975; Botella et alii, 1975), Porzuna (Vallespí et alii, 1979, 1985), Arenero de Oxígeno (Rus y Querol, 1981) y TD 11 y TG 11 de Atapuerca (Carbonell et alii, 1994; 1995; Mosquera y Carbonell, 1992).

El Complejo Inferior se aleja notablemente de las series caracterizadas por la ausencia del conjunto bifacial y más o menos ricas en cantos trabajados, como El Aculadero o Los Llanos, cuyas cadenas operativas de débitage o mixtas exhiben un claro menor desarrollo. Algo similar sucede con Pinedo, donde las cadenas operativas de façonnage están menos formatizadas y realizadas con gestos técnicos más elementales que desarrollan tipos más "toscos" en su conjunto, estableciendo el mismo criterio que en los yacimientos anteriores para los otros grupos de cadenas operativas.

Los sitios atribuibles al Achelense "pleno", como la Maya II y el Sartalejo a los que podemos añadir Áridos (aunque es un yacimiento peculiar), La Maya I terraza de $+14 \mathrm{~m}$. o Torralba (considerando que presentan elementos más "evolucionados" que los anteriores), comprenden una industria más próxima a la del Complejo Inferior, sobre todo en lo que respecta a las cadenas operativas de débitage, siendo en ocasiones francamente similar, sin embargo las mixtas y las de façonnage son más contrastables, mostrándose siempre más desarrolladas las del sitio soriano (excepto con respecto a Torralba).

La Maya I, terraza de $+8 \mathrm{~m}$. y la fase III de Atapuerca (TD11 y TG11), adscritos al Achelense final, ostentan industrias claramente diferenciadas de las nuestras. La Maya I $(\mathrm{T}+8 \mathrm{~m}$.) contiene cadenas operativas de débitage y mixtas sensiblemente menos desarrolladas, al contrario de lo que sucede con las de façonnage que se presentan más elaboradas. En Atapuerca (TD11 y TG11) disponemos de escasos datos objetivos para considerar su industria (6), las cadenas operativas mixtas se conforman claramente más progresivas que las sorianas, intuimos que sucede lo mismo con los otros dos grandes grupos de cadenas operativas.

Los yacimientos de Pleistoceno medio con industria atribuible alAchelense superior, presentan rasgos claramente paralelizables con el Complejo Superior de Ambrona: las cadenas operativas se muestran generalmente completas, prevaleciendo las de débitage y mixtas sobre las de façonnage; primacía de núcleos con explotación organizada, dominando los discoides y con amplio desarrollo de los levallois, hecho que corrobora el "elevado" índice de lascas levallois y de talones facetados; cadenas operativas mixtas con predominio de las raederas, relativamente elaboradas y con cierta estandarización, seguidas en unos casos por los denticulados (Atapuerca), y en otros por el grupo Paleolítico superior (Porzuna), dominando siempre el retoque regular, de modo simple o plano; las cadenas operativas de façonnage cuentan con bifaces en los que sobresalen los tipos muy elaborados, ovalares y amigdaloides, como los hallados en Arenero de Oxígeno, regulares y simétricos, con fuerte grado de formatización y retoque de los filos empleando el percutor poco pesado, como en Oxígeno y Porzuna, aunque de inferiores dimen-

(6) El empleo del Sistema Lógico Analítico en su caracterización explica esta situación. 


\begin{tabular}{|l|l|}
\hline \multicolumn{1}{|c|}{ Características } & \multicolumn{1}{c|}{ Yacimientos } \\
\hline $\begin{array}{l}\text { Cadenas operativas de façonnage con ausencia de bifaces y hendedores, pero ricas en cantos } \\
\text { trabajados. }\end{array}$ & $\begin{array}{l}\text { El Aculadero. } \\
\text { Los Llanos (S. Quirce del río Pisuerga) }\end{array}$ \\
\hline Cadenas operativas de façonnage y cadenas operativas mixtas, muy elementales. & Pinedo. \\
\hline Achelense. & $\begin{array}{l}\text { Complejo Inferior de Ambrona. } \\
\text { Torralba. } \\
\text { La Maya II. } \\
\text { El Sartalejo. } \\
\text { Áridos. }\end{array}$ \\
\hline Achelense final. & $\begin{array}{l}\text { Complejo Superior de Ambrona. } \\
\text { La Maya I (terraza de +8 m.). } \\
\text { Atapuerca, fase III (TD11 y TG11). }\end{array}$ \\
\hline Ausencia de cadenas operativas de façonnage. & Cuesta de la Bajada. \\
\hline
\end{tabular}

Tabla 30. Yacimientos del Pleistoceno medio, contrastados con el Complejo Inferior y Superior de Ambrona (Soria).

siones a los del Complejo Superior, los hendedores no son frecuentes, y se definen por sus siluetas equilibradas y por el empleo del percutor blando.

Como conclusión señalar que las diferencias y semejanzas existentes entre el yacimiento de Ambrona respecto a los sitios citados, hacen pensar que la industria del Complejo Inferior se sitúa en la "órbita" de Áridos, La Maya II, El Sartalejo, y Torralba (Tab. 30), y los niveles superiores de Ambrona muestran rasgos paralelizables con los adscritos al Achelense superior, donde no existe una destacada presencia de las cadenas operativas de façonnage, los núcleos están organizados (Solana de Zamborino), y la relativa estandarización de la industria permite cierta aproximación al Paleolítico medio como sucede en la fase III de Atapuerca y en Porzuna. Alejándose de esta serie los conjuntos achelenses en los que predominan las cadenas operativas de façonnage, presencia de núcleos con talla poco organizada (La Maya I), e incipiente desarrollo de las c.o levallois (Torralba y Áridos I), utensilios toscos sobre lasca, con morfotipos poco característicos (Pinedo y La Maya III), y retoque no estandarizado (Torralba).

\section{BIBLIOGRAFÍA}

ARnÁlz, M.A. (1990): "Las ocupaciones de San Quirce de Río Pisuerga: reflexiones sobre la utilización del espacio y sus implicaciones". Boletín del Seminario de Estudios de Arte y Arqueología, LVI. Valladolid: 25-37.

Arnálz, M.A. y Cuesta Romero, A. (1994): "El Yacimien- to de Paleolítico inferior de Los Llanos. San Quirce de Río Pisuerga (Palencia)”. Raña, 16:VII-XI.

Biberson, P. (1964): "Torralba et Ambrona. Notes sur deux stations acheuléennes de chasseurs d'elephants de la Vieille Castille". En Miscelanea en homenaje al Abate Breuil, I: 201-231. Instituto de Prehistoria y Arqueología. Barcelona.

Bö̈DA, E. (1986): Approche technologique du concept levallois et evaluation de son champ d'aplication: étude de trois gisements saaliens de la France. Université de París, X, 2. París.

- (1988): "Le concept Levallois et évaluation de son champs d'application". En M. Otte (ed.): L'homme de Néandertal. Actes du colloque international de Liège (4-7 décembre 1986). En J.K. Kozlowski (coord.): La mutation, 6. Service de Préhistoire. Université de Liège: 41-60.

- (1993): "Le débitage discoïde et le débitage levallois récurrent centripète". Bulletin de la Société Préhistorique Fançaise, 90 (6): 392-404.

BoËDA, E.; Geneste, J.M. y Meignen, L. (1990): “Identification de chaînes opératiores lithiques de paléolithique ancien et moyen". Paléo, 2: 43-80.

Botella, M.C. (1975): "El cazadero achelense de la Solana del Zamborino (Granada)". Actas del XIII Congreso Nacional de Arqueología. Universidad de Zaragoza. Zaragoza: 175-184.

Botella, M.C.; Vera, J.A. y Porta, J. (1975): "El yacimiento achelense de Solana del Zamborino. Fonelas (Granada)". Cuadernos de Prehistoria de la Universidad de Granada, I: 1-46.

Butzer, K.W. (1965): "Acheulian Occupation Sites at Torralba and Ambrona: their Geology". Science, 150: 1718-1722.

Carbonell, E.; Giralt, S.; Márquez, B.; Martín, A. y Mosquera, M. (1995): "El conjunto lito-técnico de la Sierra de Atapuerca en el marco del Pleistoceno

T. P., 54, n. ${ }^{\circ} 1,1997$ 
europeo". Jornadas cientificas/Workshop sobre evolución humana y los yacimientos en la sierra deAtapuerca (Medina del Campo, Valladolid. 1992), 2: 445-533.

Carbonell, E.; Guilbaud, M. y Mora, R. (1983): "Elaboration d'un Systeme d'analyse pour l'étude des eclats bruts de débitage". Dialektike: 22-40.

Carbonell, E. y Rodríguez, X.P. (1994): "Early Middle Plesitocene desposits and artefacts in the Gran Dolina site (TD4) of fhe «Sierra de Atapuerca» (Burgos, Spain)". Journal of Human Evolution, 26: 291-311.

FreEman, L.G. y Howell, F.C. (1982): "Ambrona: an early stone age site on the Spanish Meseta". The L.S.B. Leakey Foundation News, 22: 10-13.

Gladfelter, B.G. (1971): "Meseta and Campiña landforms in Central Spain. A geomorphology of the alto Henares Basin". Research Paper 130. University of Chicago.

Howell, F.C. (1965): "Yacimiento acheulense de Ambrona”. Noticiario Arqueológico Hispánico, VII (1-3): 7-23.

- (1966): "Observations on the Earlier Phases of the European Lower Paleolithic". American Anthropologist, 68 (2) part. 2: 88-201.

Howell, C.; Butzer, K.; Freeman, L.G. y Klein, R.G. (1995): "Observations on the Acheulean Occupation site of Ambrona (Soria province, Spain) with particular reference to recent investigations (1980-1983) and the Lower Occupation". Jahruch des RömischGermanischen Central Museum Mainz, 38: 33-82.

KARLIN, 1991: "Connaissances et savoir-faire: comment analyser un processu technique en Préhistoire: Introduction". En R. Mora, X. Terradas, A. Parpal y C. Plana (eds.): Tecnología y cadenas operativas líticas. Reunión Internacional, 15-18 enero de 1991. Treballs d'Arqueologia, I: 99-124. Bellaterra (Barcelona).

Mosquera. M. y Carbonell, E. (1992): "La industria lítica en Atapuerca (Burgos)". Trabajos de Prehistoria, 49: 131-154.

OrtegA, A.I. (1994): "La industria lítica de Torralba del Moral (Soria)". Studia Archaeologica, 82. Universidad de Valladolid. Valladolid.

Panera Gallego, J. (1996): “Caracterización tecnomorfológica de la industria lítica del complejo inferior de Ambrona». Espacio, Tiempo y Forma, Serie I, Prehistoria y Arqueología, 9: 103-138.

Pérez González, A. y Santonja, M. (1995): "Los yacimientos de Ambrona y Torralba". En A. Pérez-González y T. Aleixandre (eds.): IX Reunión nacional sobre cuaternario. AEQUA, 25-28 de septiembre. CSIC. Madrid.
Pérez González, A.; Santonja, M.; Gallardo, J. y AleiXandre, T. (1991): "Los yacimientos pleistocenos de Torralba y Ambrona y sus relaciones con la evolución geomorfológica del poljé de Conquezuela". VIII Reunión Nacional del Cuaternario. Valencia.

Querol, M. a A. y SANTONJA, M. (1979): El yacimiento Achelense de Pinedo (Toledo). Excavaciones Arqueológicas en España, 106. Ministerio de Cultura. Madrid.

- (1983): El yacimiento de cantos trabajados de el Aculadero (Puerto de Santa María, Cádiz). Excavaciones Arqueológicas de España, 130. Ministerio de Cultura. Madrid.

RuBIo JARA, S. (1996): “Ambrona (Soria): La industria lítica del Complejo Superior». Espacio, Tiempo y Forma, Serie I, Prehistoria y Arqueología, 9: 75-102.

Rus, I. y Querol, M. ${ }^{a}$ A. (1981): “Arenero de Oxígeno: bifaces, hendedores y triedros conservados en el Museo Arqueológico Nacional". Trabajos de Prehistoria, 38: 39-67.

Santonja, M. (1984a): "Los núcleos de lascas en las industrias paleolíticas de la meseta española". Zephyrus, XXXVII-XXXVIII, 1984-1985: 17-33.

- (1984b): Las industrias paleolíticas de la Maya I. En su ámbito regional. Excavaciones Arqueológicas en España, 135. Ministerio de Cultura. Madrid.

- (1985): El yacimiento de El Sartalejo (valle del Alagón, Cáceres). Estudio preliminar. Series de Arqueología Extremeña, 2. Universidad de Extremadura. Cáceres.

- (1986): "Valgrande (Puebla de Yeltes, Salamanca): Área de talla y sitio de ocupación del Paleolítico Medio". Numantia II. Investigaciones Arqueológicas en Castilla y León: 33-85.

Santonja, M.; López, N. y Pérez González, A. (1980): Ocupaciones achelenses en el valle del Jarama. $\mathrm{Pu}-$ blicaciones de la Diputación provincial. Madrid.

SCHWENZER, J.E. (1937): Zur Morphologie des zentralspanichenm Hochlandes. Geogr. Abhandl, 3, 10. Stuttgart.

Vallespí, E.; Ciudad, A. y García Serrano, R. (1979): Achelense y Musteriense de Porzuna (Ciudad Real). Materiales de superficie I (colección E. Oliver). Museo de Ciudad Real. Estudios y Monografías, 1. Ciudad Real.

- (1985): Achelense y Musteriense de Porzuna (Ciudad real). Materiales de superficie II (Muestras de las colecciones de A. Retamosa y M. Expósito). Universidad de Castilla-La Mancha. Ciudad Real. 